DEMOGRAPHIC RESEARCH

VOLUME 34, ARTICLE 27, PAGES 761-796 PUBLISHED 04 MAY 2016

http://www.demographic-research.org/Volumes/Vol34/27/

DOI: 10.4054/DemRes.2016.34.27

Research Article

\title{
Birth seasonality in Sub-Saharan Africa
}

\section{Audrey M. Dorélien}

(C) 2016 Audrey M. Dorélien.

This open-access work is published under the terms of the Creative Commons Attribution NonCommercial License 2.0 Germany, which permits use, reproduction \& distribution in any medium for non-commercial purposes, provided the original author(s) and source are given credit. See http://creativecommons.org/licenses/by-nc/2.0/de/ 


\section{Table of Contents}

$\begin{array}{lll}1 & \text { Introduction } & 762\end{array}$

$\begin{array}{lll}1.1 & \text { Review } & 762\end{array}$

2 Data $\quad 763$

$\begin{array}{lll}2.1 & \text { Demographic and health surveys data } & 763\end{array}$

$\begin{array}{lll}2.1 .1 & \text { Sampling weights } & 763\end{array}$

$\begin{array}{ll}\text { 2.1.2 } & 764\end{array}$

$\begin{array}{lll}2.2 & \text { FAO ecological zone data } & 767\end{array}$

3 Methods $\quad 767$

$\begin{array}{lll}4 & \text { Country level results } & 769\end{array}$

$\begin{array}{lll}4.1 & \text { Periodicity and seasonality } & 769\end{array}$

4.2 Amplitude $\quad 771$

$\begin{array}{lll}\text { 4.3 } & \text { Maternal characteristics } & 771\end{array}$

$\begin{array}{lll}5 & \text { Ecological zone results } & 774\end{array}$

6 Discussion and conclusion $\quad 776$

$\begin{array}{lll}7 & \text { Acknowledgements } & 777\end{array}$

$\begin{array}{ll}\text { References } & 778\end{array}$

$\begin{array}{lll}8 & \text { Appendix A } & 780\end{array}$

$9 \quad$ Appendix B $\quad 784$

$\begin{array}{lll}10 & \text { Appendix C } & 789\end{array}$

$\begin{array}{lll}11 & \text { Appendix D } & 794\end{array}$ 


\title{
Birth seasonality in Sub-Saharan Africa
}

\author{
Audrey M. Dorélien ${ }^{1}$
}

\begin{abstract}
INTRODUCTION

Despite humans' ability to reproduce throughout the year, almost all human populations exhibit seasonal variation in reproduction. The seasonality of births has been extensively studied in North America, Europe, and East Asia but less so in African settings. This paper is the first to systematically test for and document birth seasonality in Sub-Saharan Africa.
\end{abstract}

\section{DATA AND METHODS}

Birth data from the Demographic and Health Surveys are aggregated by country and ecological zone. The monthly time series of births are then de-trended and converted to a percent deviation from the annual monthly mean. Finally, we calculate the periodicity of the de-trended monthly birth time series using Fourier spectral analysis and ordinary least squares regression.

\section{RESULTS}

At the national level, births are indeed seasonal with only a few exceptions. However, we find large degrees of variation in the amplitudes (i.e., from five percent to 65 percent) and patterns (i.e., unimodal, bimodal, etc.) of seasonality across regions. Birth patterns varied with levels of maternal education, religion, and residence (i.e., urban vs. rural). Typically, mothers with lower levels of education and those residing in rural locales exhibited greater seasonal fluctuations in births. Births in West and Central African ecological zones were highly seasonal, while births in many Eastern and Southern ecological zones were not seasonal. The Eastern and Southern zones were large and included strongly heterogeneous environments and people; these heterogeneities may have masked some of the seasonal patterns.

\footnotetext{
${ }^{1}$ University of Minnesota at Minneapolis, U.S.A, E-Mail: dorelien@umn.edu.
} 


\section{Introduction}

Despite humans' ability to reproduce throughout the year, human populations often exhibit seasonal variation in reproduction. This paper aims to document birth seasonality in Sub-Saharan Africa (SSA) in more detail than previously achieved. We use birth data from the Demographic and Health Surveys to systematically document, test, and compare birth seasonality in SSA. We also examine the stability of birth seasonality over two decades. When possible, we disaggregate the data by urban or rural residence, socioeconomic status, and religion to assess whether birth month is correlated with various aspects of family background.

\subsection{Review}

Seasonality of births has been extensively studied in North America, Europe, and East Asia but less so in African settings. The existing research on birth seasonality in SSA (specifically, Kenya, Tanzania, Democratic Republic of Congo, and South Africa), summarized below, has focused on small populations and/or short time periods.

Using Kenyan birth data from January 1979 to June 1982, Ferguson (1987) was able to identify a national pattern consisting of a strong peak in September and a secondary peak in April-May. The September amplitude (the percentage deviation above the expected monthly number of births based on a uniform distribution of births across the year) ranged from 11 to 21 percent above the monthly average. This study may suffer from significant selection bias; Ferguson's data came from district birth registers, but in many districts only a small fraction of births were registered during that time period. In contrast to the national pattern described by Ferguson (1987), a high degree of birth seasonality for births occurring between 1958 and 1983 was found for the Ngisonyoka Turkana in Northwest Kenya (Leslie and Fry 1989). More than half of the births in the Ngisonyoka Turkana occurred between March and June; annual peaks were generally observed in April and May and exhibited an amplitude of approximately 56 percent. Leslie and Fry's sample only included 495 births, and the Turkana did not have any written birth records, so the information was collected from interviews to create reproductive histories. Bantje (1987) compiled birth data from nine rural hospitals throughout Tanzania. The births occurred between the 1940s and 1985, and records were kept for varying time periods throughout the locations. Only four locations exhibited clear seasonal patterns. In these regions, which all exhibit yearlong transmission of malaria, the peaks occurred between September and November with an amplitude of approximately 26 percent. Mulder (1992) looked at birth seasonality in the Esai Datoga, semi-nomadic pastoralists in northern Tanzania. The Datoga had a major peak in May, and 44 percent of the births occurred between April and July. 
Bailey et al. (1992) documented the birth seasonality of Lese subsistence farmers and the sympatric Efe pygmy foragers in the region then known as north-east Zaire (currently Democratic Republic of Congo). All births between January 1980 and August 1987 were monitored. A total of 147 births occurred during the study period. Among the subsistence farmers, births peaked during the summer months. The peak amplitude was over 100 percent. No significant seasonal fluctuations were observed among the neighboring Efe foragers.

Lam and Miron (1991) described birth seasonality in South Africa from 1950 to 1984 using data from published registries of vital statistics. The data were disaggregated into white and black births. Black births peaked in September and had a trough in May. The birth amplitude was approximately 10 percent. Birth seasonality for white South Africans was much less pronounced, the amplitude was less than five percent, but they also exhibited a September peak. Cowgill (1966), using South African birth data from 1935 to 1958 , described the same pattern.

These studies indicate that seasonal patterns do exist in SSA and that the amplitude can vary from five to over 100 percent depending on the population. The highest birth amplitudes were observed in pastoral settings and in areas of high malaria transmission. However, it is difficult to determine whether a consistent "African" pattern emerges.

\section{Data}

\subsection{Demographic and health surveys data}

The Demographic and Health Surveys (DHS) are nationally representative surveys of women of childbearing age carried out in developing countries. There are two samples in our study. One includes every available SSA survey (i.e., 81 surveys, 31 countries); the other only includes surveys with geographic coordinates (i.e., 51 surveys, 26 countries). We were able to use the DHS because every woman aged 15-49 years was asked the month and year of the birth of every child she ever had. In addition to the month and year of birth, we also extracted the following variables: rural/urban classification, religion, maternal education status, whether or not the child is alive, and age at death of deceased children. The geocoded surveys allowed us to merge the DHS data with other spatial datasets in order to obtain additional covariates.

\subsubsection{Sampling weights}

We utilized the DHS sampling weights in our analysis. However, when we aggregated by ecological zone, for each survey, we estimated the population in the country at the time of the survey, which we call $N$. Next, for each survey, we computed inflating factors by 
dividing each weight by the sample size $(n)$ and multiplying it by $N$. Finally, when we pooled several surveys, for each zone $k$, we divided the inflation factors of all women in zone $k$ by the average inflation factor in zone $k$. This resulted in normalized weights that sum to the sample size in each zone and give more weight to surveys from more populated countries.

\subsubsection{DHS data quality}

As with most survey data, we were restricted to births of children whose mothers had not died between the time of their birth and the interview date. The DHS deals with incomplete observations by employing an imputation strategy (Croft 1990). Observations with imputed birth month and or birth year were dropped from our samples. The numbers of imputed observations ranged from less than one percent in some countries to 60 percent in others, but on average, 12 percent of the observations were dropped (Table 1). The imputed/dropped observations were more likely to be from older or dead children (i.e., recall error), rural areas, and children born to uneducated mothers $(p<0.001)$. If seasonality is primarily driven by poorer households, in regions with large amounts of imputed observations, we may underestimate the magnitude of birth seasonality.

Two other data quality issues with the DHS are birth displacement and deliberate omissions of recent births. In these cases, interviewers may change the date of birth (displacement) or omit the birth of a child in order to avoid administering a lengthy health module (Arnold 1990; Pullum 2006; Schoumaker 2011). However, while this may be a problem for estimating levels of fertility, it does not necessarily introduce bias in our estimation of birth seasonality. The health module ${ }^{2}$ usually includes information regarding children born five years before the survey date; therefore, there is reason to believe that births are displaced from the fifth to the sixth year before the survey date (Kirk and Pillet 1998; Pullum 2006). However, since only two years are affected in each survey round, the problem is likely "diluted," especially with the inclusion of subsequent surveys. Additionally, if there is a strong correlation between the month of the interview and the birth month, the results would be biased. To test for this, in each country, we looked at the correlation between interview month and birth month. In some countries, birth month was positively correlated with interview month. We suspect this would create a downward bias in our estimates of birth amplitude because most interviews were conducted toward the end of the year and, as we describe later, for most SSA countries, the peak birth month is in the first half of the year.

Women may be less likely to include children that have died in their survey responses. We compared the seasonal birth patterns of children that have died with children alive on the survey date. We found that children who died as infants had similar birth seasonality patterns as children who survived infancy; however, in some locations,

\footnotetext{
${ }^{2}$ Certain health questions and anthropometric measurements are only taken on children under the age of five.
} 
the peak infant survival month mirrored the peak birth month, suggesting that there could be a small inflation in peak birth amplitude due to the exclusion of children who have died. 
Dorélien: Birth seasonality in Sub-Saharan Africa

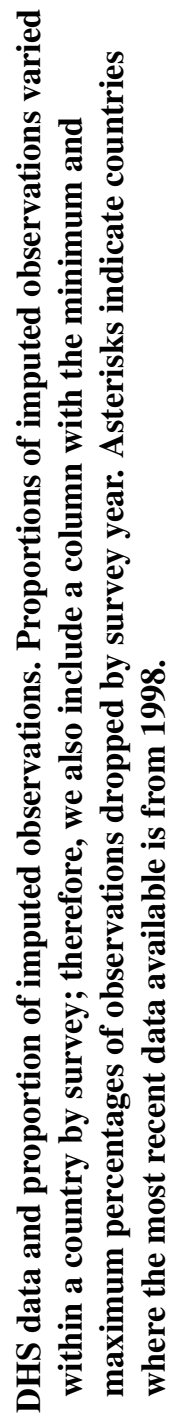

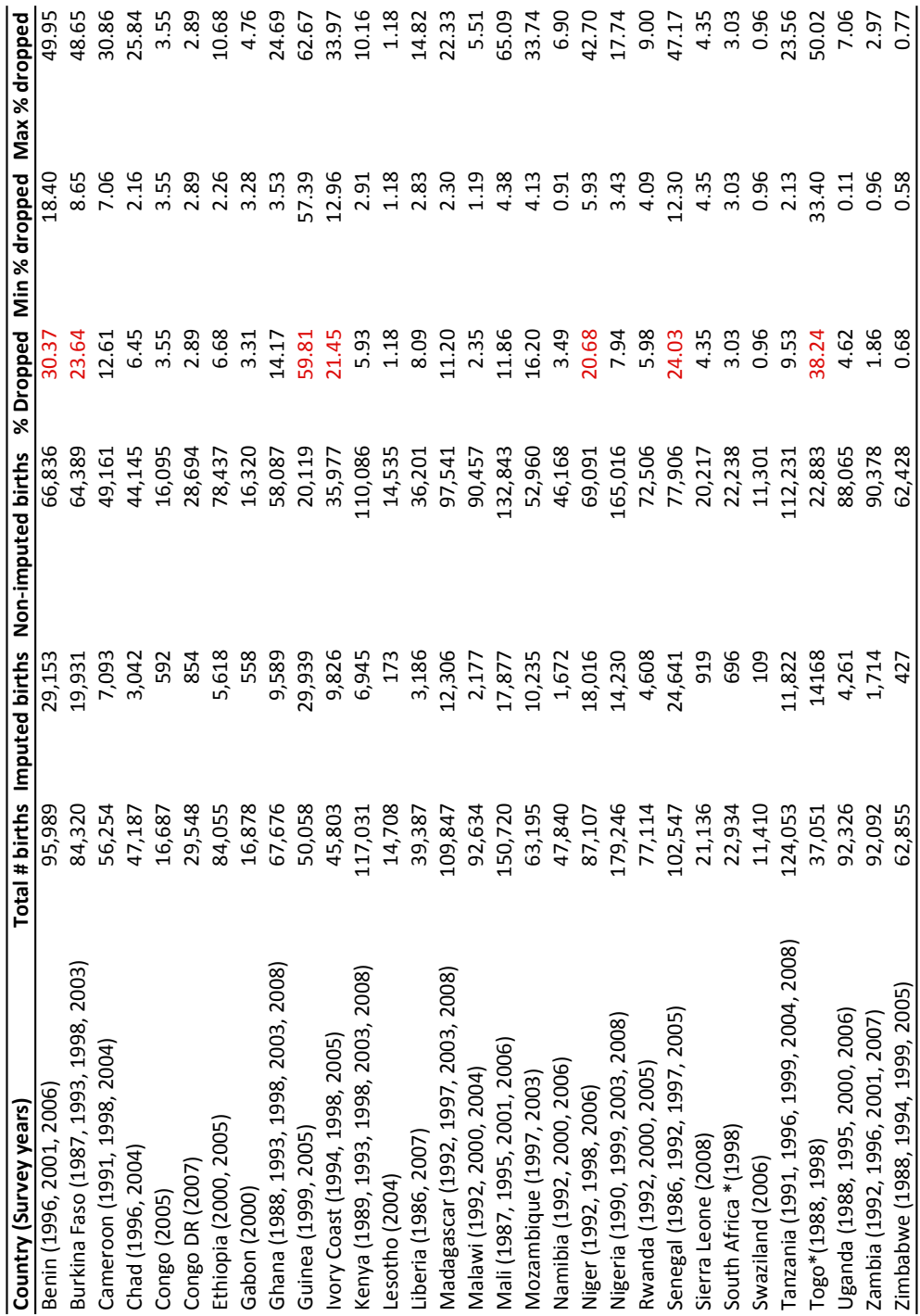

$\frac{0}{0}$ 


\subsection{FAO ecological zone data}

If birth seasonality is primarily driven by environmental factors, describing seasonal birth patterns at a country level may obfuscate important patterns, especially for large countries. Therefore, we obtained a map of the different ecological zones and farming systems in SSA from the Food and Agricultural Organization (FAO). The classification is based on the available natural resource base, including water, land, grazing areas and forest, the climate, of which altitude is one important determinant, the landscape, including slope, and farm size, tenure and organization. Additionally, it takes into account the dominant patterns of farm activities and household livelihoods, including field crops, livestock, trees, aquaculture, hunting and gathering, processing and off-farm activities, and the main technologies used, which determine the intensity of production and integration of crops, livestock and other activities (Dixon, Gulliver, and Gibbon 2001, page 11).

The 14 ecological zones identified are irrigated, tree crops, forest-based, rice and tree crops, highland perennial, highland temperate mixed, root crop, cereal root crop mixed, large commercial smallholder, agro-pastoral, pastoral, arid, and coastal fishing. A more detailed description of the different zones can be found in Dixon, Gulliver, and Gibbon (2001), Farming Systems and Poverty: Improving Farmers' Livelihoods in a Changing World. In instances in which the ecological zones were not contiguous and were located in distant regions, we divided the zones. The geocoded DHS clusters were spatially merged with the ecological zones so that birth seasonality could be analyzed at the commensurate scales.

\section{Methods}

It is important to note that the methods used to describe seasonal fluctuations in births vary across studies. To facilitate comparisons, monthly birth rates are converted to birth amplitudes. In this paper, amplitude is defined as the percent deviation from the annual monthly mean, indexed at zero or 100. Other parameters of interest include peak and trough amplitudes and months and the shape of the birth distribution.

We performed the analysis by aggregating births by country and ecological zones. We followed the methods in He and Earn (2007) to de-trend and scale the monthly birth data. The following equations were used:

$$
\begin{gathered}
\bar{X}_{i}=\frac{1}{12} \sum_{j=1}^{12} X_{i j} \\
C_{i j}=\frac{(\text { Days in year } i) / 12}{\text { Days in month } j \text { of year } i}
\end{gathered}
$$




$$
\begin{aligned}
Y_{i j} & =\frac{C_{i j} X_{i j}-\bar{X}_{i}}{\bar{X}_{i}} \\
Z_{j} & =\frac{1}{N_{y r}} \sum_{j=i}^{i+10} Y_{i j}
\end{aligned}
$$

We aggregated the observations from the DHS to obtain the monthly number of births for month $j$ in year $i$, represented by $X_{i j}$. Equation 1 represents the average number of births, $\bar{X}_{i}$, in a month of average length in year $i$. Equation 2 defines the scaling factor, $C_{i j}$, used to correct for the variation in month lengths. In equation 3 , we define the scaled, month-length-corrected monthly amplitude, $Y_{i j} .{ }^{3}$ Finally, equation 4 represents the average monthly amplitude over the periods $1980-1990$ and 1990-2000, $Z_{j}$, which was computed by averaging the monthly amplitudes across years $\left(N_{y r}=11\right)$. We also calculated the maximum amplitude, defined as the maximum difference between the monthly amplitude and the mean.

We calculated the periodicity of the scaled, corrected time series data from 1980 to the most recent available observations ${ }^{4}$ (equation 3) using Fourier spectral analysis (Cancho-Candela, Andrés-de Llano, and Ardura-Fernández 2007; He and Earn 2007; Torche and Corvalan 2010). Fourier spectral analysis identifies how the proportion of total variance in a time series is distributed across different frequencies of sine and cosine functions. If a large variance is identified at a particular frequency, we can conclude that there is a strong signature of the respective frequency (or period) in the data. Spectral analysis was performed using MATLAB $($ R2010b, The MathWorks, Natick, MA). The significance of the seasonal peaks was determined by comparing the results to a randomized spectrum (Bjørnstad et al. 1998).

We also measured seasonality during the period 1980-2000 (21 years) using ordinary least squares (OLS) regression. We took the de-trended monthly births (equation 3) and regressed them against monthly dummies. One benefit of this analysis is that the $R^{2}$ value corresponds to the percentage of the variation in births that is due to seasonality and not to a trend in the data. In other words, if $R^{2}$ is large, then seasonal fluctuations are a dominant source of variation in births.

\footnotetext{
${ }^{3}$ Because we divided by the annual mean, we did not need to standardize the population size. We only used the counts of births instead of birth rates because we assume that the size of the population does not vary greatly over the year.

${ }^{4}$ The spectral analysis results were the same when we only included data from 1980 to 1999.
} 


\section{Country level results}

For a large swath of SSA, the DHS is an appropriate database to calculate birth seasonality because it includes large sample sizes. It falls short in countries and ecological zones with few surveys, but this situation will improve with the inclusion of future implementations of the DHS. In particular, for countries with low peak birth amplitudes (i.e., less than 10 percent), large samples are needed to tease out birth seasonality from stochastic variation.

\subsection{Periodicity and seasonality}

Births in most countries in Sub-Saharan Africa are seasonal; however, there do appear to be clusters of countries that do not have regularly recurring intra-annual fluctuations (e.g., Lesotho, Togo, Swaziland, and Zimbabwe) or have very weak periodicity (e.g., Malawi, South Africa, and Zambia)(see Appendix A for periodograms). The low $R^{2}$ values from the OLS regression for Lesotho, Togo, South Africa, Swaziland, Zambia, and Zimbabwe confirm this (Table 2). The OLS results for Malawi indicate that seasonal fluctuations are the dominant source of variation in births. This observation can be reconciled with the results of the spectral analysis by the high degree of inter-annual variation. The lack of a clear seasonal pattern in Togo may be due to the fact that 38 percent of the observations were dropped. For Swaziland and South Africa, only one DHS is available, and therefore the number of observations was not large; if birth seasonality does exist and is weak, it may be overwhelmed by stochastic fluctuations. Malawi, Zambia, and Zimbabwe each have three to four surveys and have very few imputed observations, so the lack of seasonality is more likely real.

Three patterns of birth seasonality emerge. Birth seasonality is mainly unimodal in Burkina Faso, Cameroon, Congo, Democratic Republic of Congo, Gabon, Ghana, Guinea, Ivory Coast, Liberia, Madagascar, Mali, Nigeria, Rwanda, and Sierra Leone (see Ivory Coast panel in Figure 1 as an example and Appendix B). With the exception of Madagascar, these are all countries in West and Central Africa. Births are bimodal in Benin, Chad, Ethiopia, Mozambique, Niger, and Senegal (see Chad panel in Figure 1 as an example and Appendix B). For Kenya, Tanzania, Uganda, and Namibia, the spectral analysis indicates the presence of an annual pattern (see Appendix A), but the shape of the pattern is not easily described. Nonetheless, they all have a trough in November (see Kenya panel in Figure 1 as an example and Appendix B). Finally, for countries with no clear birth seasonality (i.e., Lesotho, Malawi, South Africa, Swaziland, Togo, Zambia, and Zimbabwe), the pattern is generally flat (see Zimbabwe panel in Figure 1 as an example and Appendix B). 


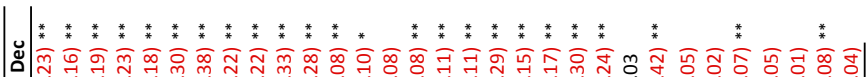

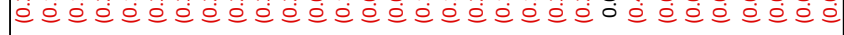

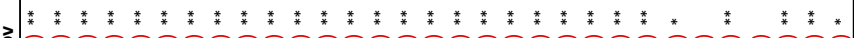

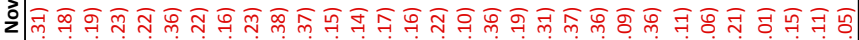

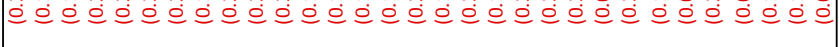

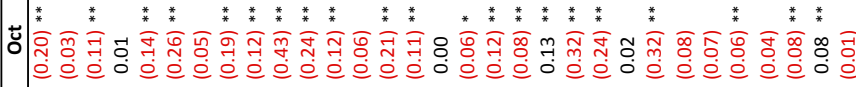

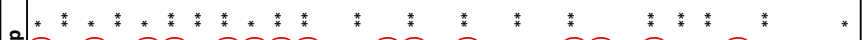

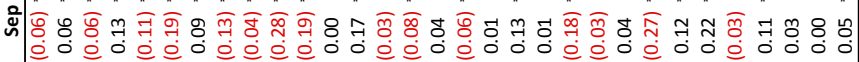

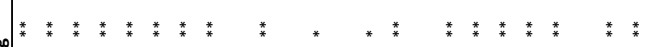

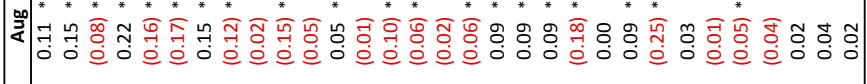

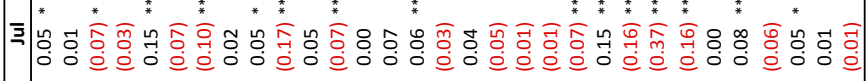

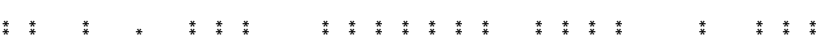

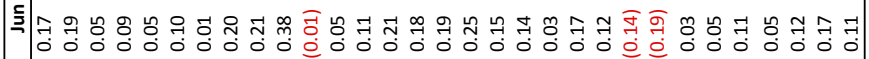

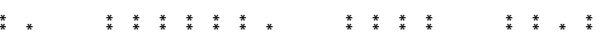

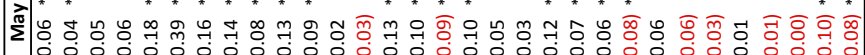
0000000000000000000000000000000

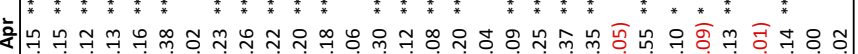

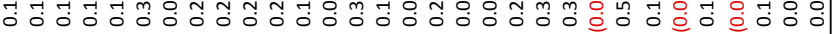

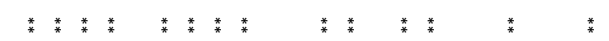

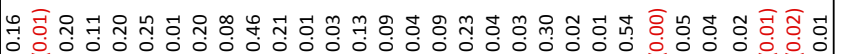

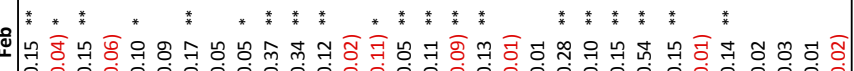

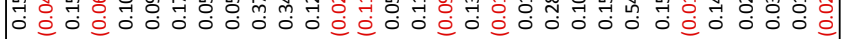
* * * * * * *

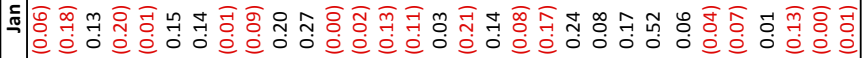

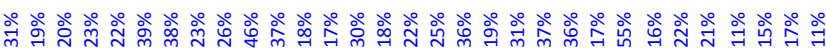




\subsection{Amplitude}

The average maximum monthly amplitude ranged from five to 65 percent, and the 20year average from 1980 to 2000 ranged from 11 to 55 percent (Table 2. The largest amplitudes were found along the West African coast. The following countries had peak amplitudes of approximately 40 percent or above: Guinea, Sierra Leone, Ivory Coast, and Nigeria (Figure 1, Table 2, and Appendix B). With a few exceptions, the other countries on the West African coast had peak birth amplitudes of approximately 30 percent. The DR Congo and Rwanda in Central Africa also exhibited large peak amplitudes (Figure 1 and Table 2). As shown in the examples in Figure 1, the amplitude and pattern of birth seasonality appears stable over the period from 1980 to 2000 .

\subsection{Maternal characteristics}

Disaggregating the results by mother's educational attainment, we found that women with different educational backgrounds have different seasonal fertility patterns. In the majority of countries in our sample, mothers with no education and/or only primary education drove birth seasonality (Figure 2a shows the results for Nigeria as an example). On the other hand, in Burkina Faso and Senegal, the seasonal fertility patterns of women with no education were relatively flat compared to those with education (Figure $2 \mathrm{~b}$ shows the results for Senegal as an example). 
Figure 1: $\quad$ Examples of birth seasonality pattern by country (black $=1980-1990(11$ years $)$, red $=1990-2000(11$ years $))$. Dates near country names indicate the earliest and latest surveys used in each country. See appendix for examples grouped by region.

Ivory Coast (1994, 2005)

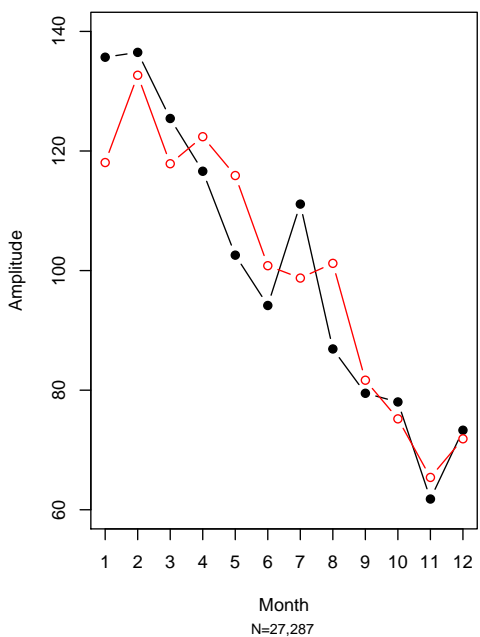

Kenya (1989, 2009)

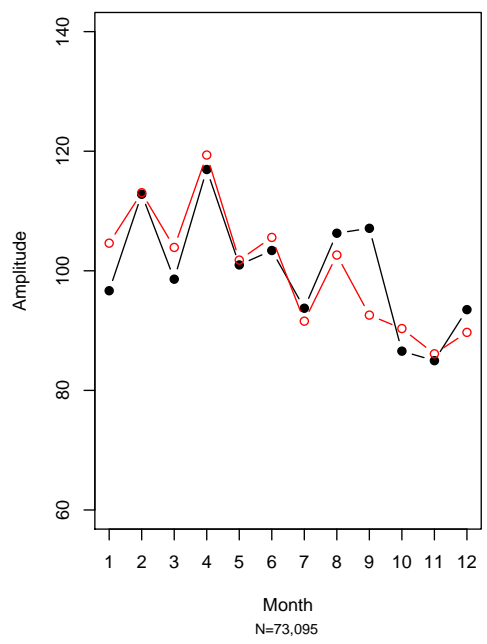

Chad (1996, 2004)

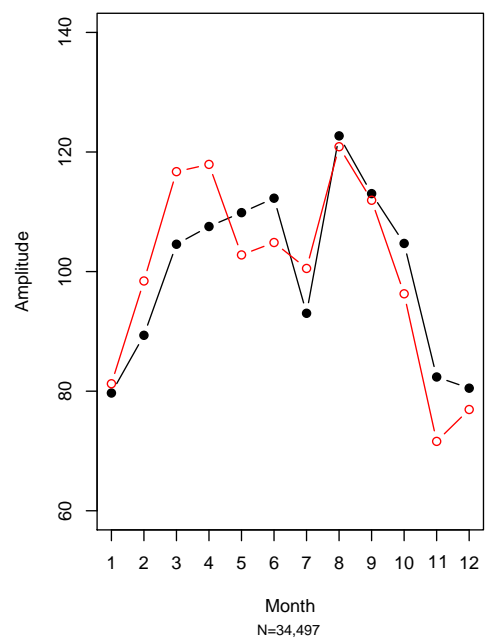

Zimbabwe (1988, 2006)

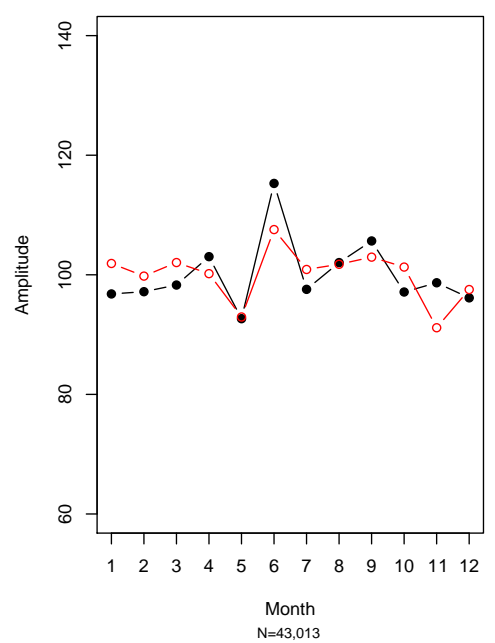


Figure 2: $\quad$ Average monthly birth amplitude by mother's level of education, type of residence, and religion for Nigeria and Senegal, 1990-2000 (11 years). The bars represent 95 percent confidence intervals.

A. Nigeria
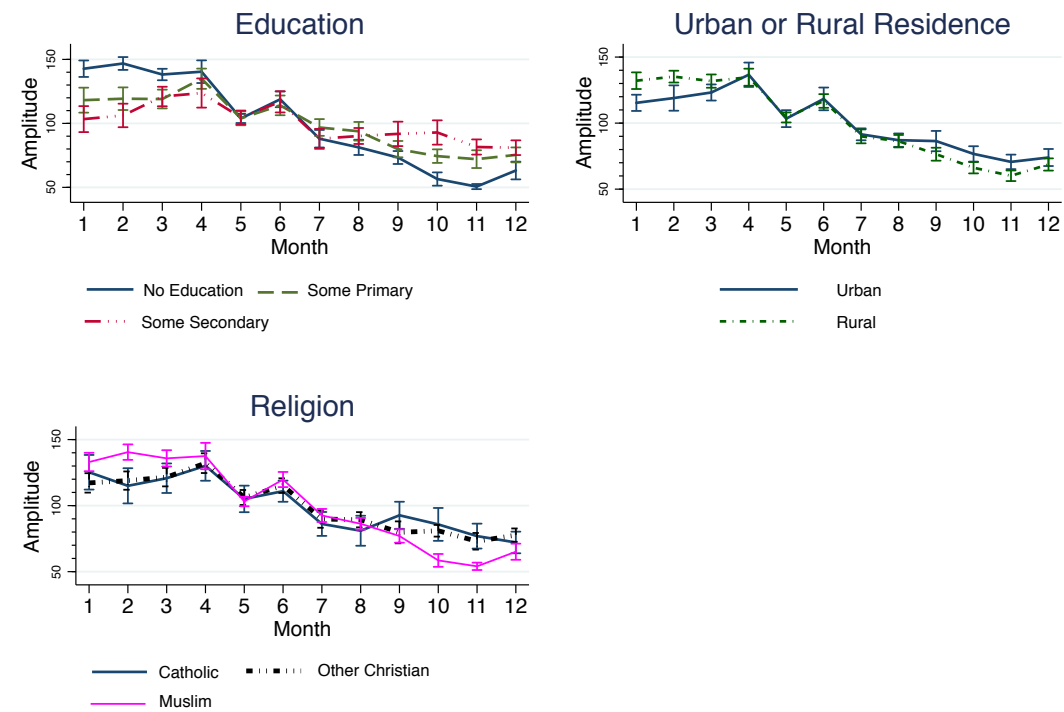

B. Senegal
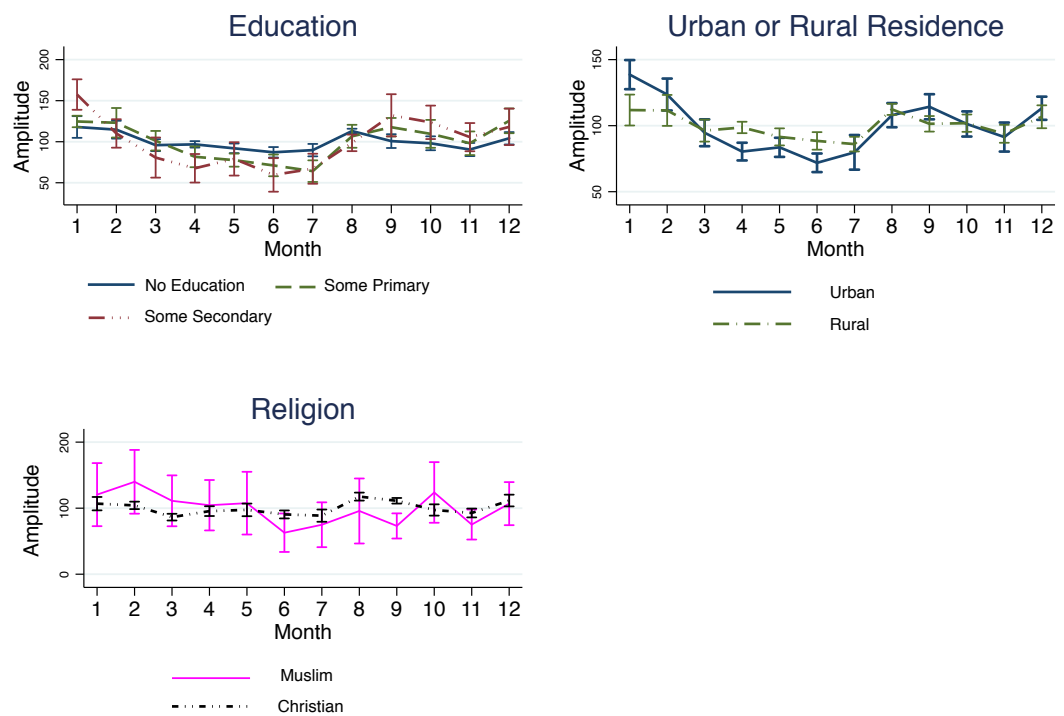

http://www.demographic-research.org 
On average, birth seasonality is of the same magnitude or stronger in rural areas compared to urban areas (Figure 2a). However, the amplitude of birth seasonality was stronger in urban areas of Gabon, Ghana, and Senegal (Figure 2b shows the results for Senegal as an example). These countries had relatively high levels of urbanization (84, 48, and 41 percent, respectively) in 2005 ( Population Reference Bureau Datafinder www.prb.org/DataFinder/Geography.aspx?loct=4).

Religion may have an impact on birth seasonality, but the relationship may vary across countries. Based on within country comparisons, seasonal birth patterns do differ by religion (Figure 2). Outside of Southern Africa, we did not observe a large increase in September births in populations that observe Christmas.

\section{Ecological zone results}

Based on the results shown in the periodograms, all ecological/farming zones located in West Africa have a strong seasonal birth signal (i.e., the dominant period is one year). Births in Madagascar and Central Africa's forest-based zones and in Madagascar's tree crop zones were also seasonal. On the other hand in Southern and Eastern Africa, births were not seasonal (i.e., the annual peaks were not significant) in any of the ecological zones except for highland perennial (East Africa), root crop (East and Southern Africa), and maize mixed systems (East and Southern Africa)(Table 3, and Appendix C-D).

The OLS results were highly correlated with the periodogram results. With one exception, whenever seasonal fluctuations explained more than 34 percent of the fluctuations in births, the periodogram also indicated a seasonal pattern. In regions with a clear annual period, the largest birth amplitudes (i.e., amplitudes greater than 30 percent) were found in irrigated, pastoral, and forest-based farming systems in West and Central Africa (Table 3). According to OLS regression, the East African Pastoral zone also had high seasonal birth amplitudes, with peaks occurring at the beginning of the year, but the periodogram results indicated that this was not consistent across years. 


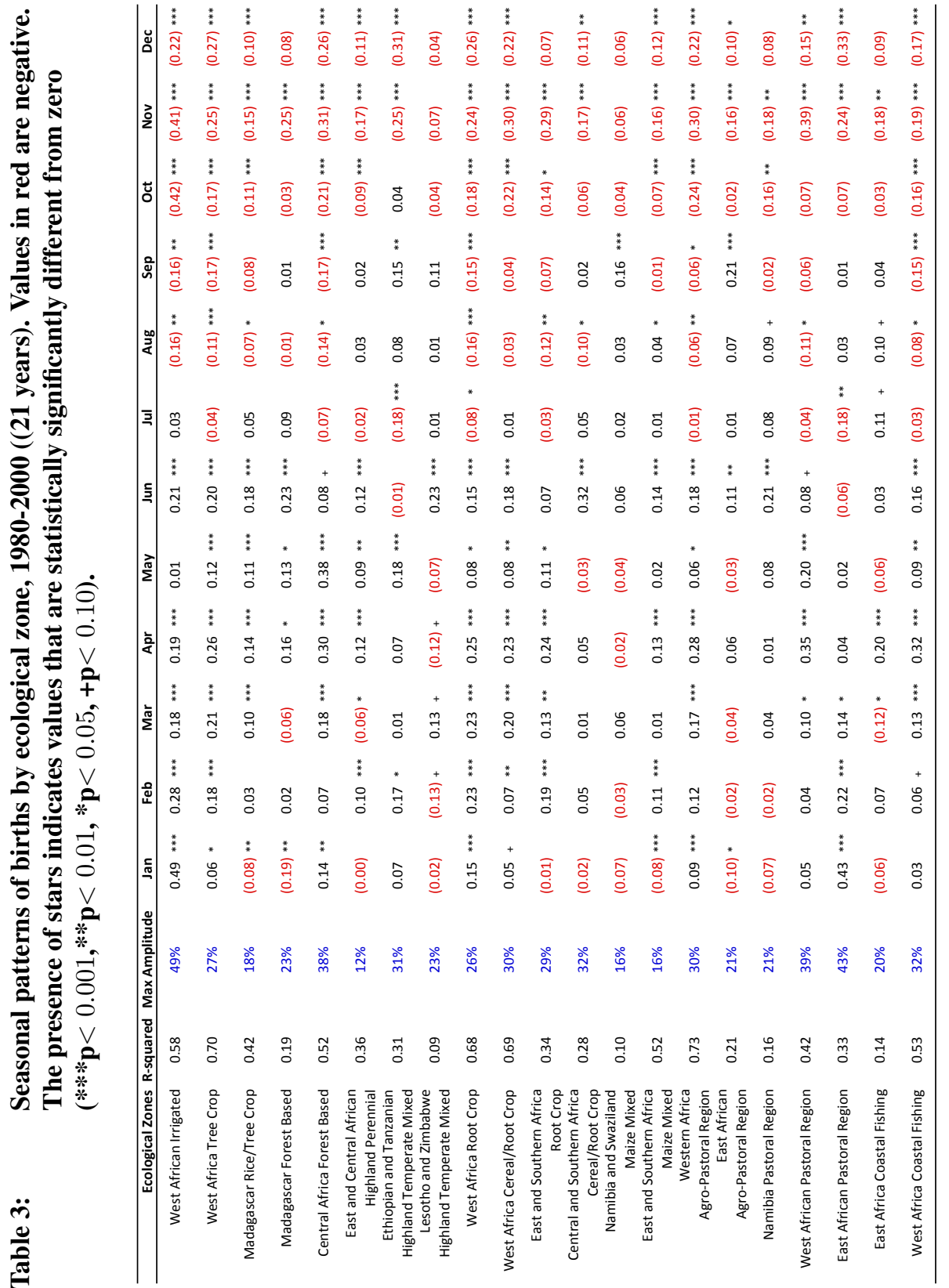




\section{Discussion and conclusion}

This study is the first to provide contemporary documentation of birth seasonality for most of Sub-Saharan Africa. Seasonality of births is quantitatively important; amplitudes are large and are a dominant source of variation in births (Table 2). For many countries in SSA, the birth amplitudes are among the highest observed in modern times. Direct comparison of our findings with earlier cited work on SSA birth seasonality are often not appropriate because of differences in scale and issues of data quality. Nevertheless, the magnitude and pattern of South Africa birth seasonality was the same in this study and in the Lam and Miron (1991); the quality of data used by Lam and Miron (1991) was relatively high and the study was conducted at a national scale. All the same, the SSA estimates of birth seasonality are within the ranges of historical amplitudes described in the introduction section and documented in developed countries (Règnier-Loilier and Rohrbasser 2011). A single "African pattern" does not emerge, but there is evidence of certain regional patterns of birth seasonality (see Appendix B for illustrations of birth seasonality patterns grouped by region). The one consistent trend across SSA regions is the dominance of a November trough in births, which corresponds to conceptions in February (this is discussed in greater detail below).

A lot of environmental and cultural heterogeneity can be found within countries in SSA; therefore, the lack of an identifiable seasonal pattern in certain locations may be due to the scale of the study. For instance, in our analysis of birth seasonality across ecological zones, we found seasonality in West Africa but very little in Southern and Eastern Africa. A more detailed farming/ecosystem zone may have been more appropriate for regions such as East Africa that are known for their climatic variability. Alternatively, other ecological factors not captured by the FAO ecological zones may be more relevant for birth seasonality. In many West African countries, births are concentrated at the beginning of the year; therefore, despite using large units of aggregation, we were able to find consistent seasonal birth patterns.

Potential drivers of SSA birth seasonality fall within these categories: social factors that influence coital frequency and timing, such as marriage time preference and labor migration; climatological and energetic factors that affect conception probability given intercourse, such as temperature and energy expenditure; and factors that can increase the probability of fetal loss, such as disease incidence (Panter-Brick 1996; Ellison, Valeggia, and Sherry 2005; Lam, Miron, and Riley 1994).

Labor migration may help explain the persistent November trough in births. Hinde and Mturi (2000) found a similar November trough in their Tanzanian study and attributed it to a reduction in February conceptions due to migrant laborers returning to work after spending December and January at home for the holidays. Seasonal labor migration may also be a driving force in West Africa, where conceptions typically peak during the rainy season, when migrants return home to plant, and drop during the drier months, when 
migrants leave to find work. In contrast, for the majority of countries in Central Africa and many in East Africa, conceptions drop during the rainy season (which corresponds with the hunger season) and increase in the dry season, highlighting the role of seasonal fluctuations in energetic balance. Within a country, one might expect higher seasonality in energy expenditures in rural areas. However, we did not find large differences between urban and rural locations; this could be due to the fact that food prices in urban areas may also be high during the hunger period, resulting in a similar pattern of seasonal fluctuations with respect to the energetic balance. There was no clear correlation between the wet/dry season and birth seasonality in Southern Africa; we hypothesize that the presence of a birth peak in September in most of these countries is related to the Christian holidays in December. The latter is consistent with findings from Lam and Miron (1991) and Cowgill (1966), which documented a September peak in births in South Africa.

In most SSA countries, women with more education and thereby higher economic status exhibit fewer seasonal fluctuations in birth patterns compared to women with less education, which could indicate that they are "shielded" from many drivers of birth seasonality.

One of the limitations of this study is that we used survey data rather than vital registration data to calculate birth seasonality. Many other studies (Mulder 1992; Leslie and Fry 1989; Panter-Brick 1996; Chatterjee and Acharya 2000) have also used retrospective survey data to measure birth seasonality, and until there is consistent vital registration in Sub-Saharan Africa, the DHS is one of the best and most available sources to measure historical patterns.

\section{Acknowledgements}

I benefited from conversations with Bruno Schoumaker, and from seminar participants at IRI at Columbia University. I would also like to thank the editor and reviewers for their constructive comments. Financial support was provided by the National Institute for Child Health and Human Development, Grant No. R24HD047879, to the Office of Population Research at Princeton University. I was also supported by a NICHD Grant No. R24HD041023, to the Minnesota Population Center at the University of Minnesota. 
Dorélien: Birth seasonality in Sub-Saharan Africa

\section{References}

Arnold, F. (1990). An Assessment of DHS-I Data Quality. Tech. rep., Marco Systems Inc.

Bailey, R.C., Jenike, M.R., Ellison, P.T., Bentley, G.R., Harrigan, A.M., and Peacock, N.R. (1992). The ecology of birth seasonality among agriculturalists in central Africa. J Biosoc Sci 24(3): 393-412.

Bantje, H. (1987). Seasonality of births and birthweights in Tanzania. Social Science \& Medicine 24(9): 733-739.

Bjørnstad, O., Stenseth, N., Saitoh, T., and Lingjærde, O. (1998). Mapping the regional transition to cyclicity in clethrionomys rufocanus: Spectral densities and functional data analysis. Researches on Population Ecology 40: 77-84. URL http://dx. doi.org/10.1007/BF02765223. 10.1007/BF02765223.

Cancho-Candela, R., Andrés-de Llano, J., and Ardura-Fernández, J. (2007). Decline and loss of birth seasonality in Spain: analysis of 33421731 births over 60 years. Journal of Epidemiology and Community Health 61(8): 713.

Chatterjee, U. and Acharya, R. (2000). Seasonal variation of births in rural West Bengal: Magnitude, direction and correlates. Journal of Biosocial Science 32: 443-458.

Cowgill, U.M. (1966). The season of birth in man. Man 1(2): 232-240.

Croft, T. (1990). DHS Data Editing and Imputation. Tech. rep., Macro International.

Dixon, J., Gulliver, A., and Gibbon, D. (2001). Farming systems and poverty: Improving farmers' livelihoods in a changing world. FAO and World Bank. URL http:// Www. fao.org/docrep/003/Y1860E/y1860e00.HTM.

Ellison, P., Valeggia, C., and Sherry, D. (2005). Seasonality in Primates: Studies of Living and Extinct Human and Non-Human Primates, Cambridge Univ Pr, chap. 13 Human birth seasonally: 379-399.

Ferguson, A.G. (1987). Some aspects of birth seasonality in Kenya. Soc Sci Med 25(7): 793-801.

He, D. and Earn, D. (2007). Epidemiological effects of seasonal oscillations in birth rates. Theoretical Population Biology 72(2): 274-291.

Hinde, A. and Mturi, A.J. (2000). Recent trends in Tanzanian fertility. Population Studies 54(2): 177-191. doi:10.1080/713779080. PMID: 11624634.

Kirk, D. and Pillet, B. (1998). Fertility levels, trends, and differentials in Sub-Saharan Africa in the 1980s and 1990s. Studies in Family Planning 29(1): 1-22.

Lam, D.A. and Miron, J.A. (1991). Seasonality of births in human populations. Soc Biol 
38(1-2): 51-78.

Lam, D.A., Miron, J.A., and Riley, A. (1994). Modeling seasonality in fecundability, conceptions, and births. Demography 31(2): 321-346. doi:10.2307/2061888.

Leslie, P.W. and Fry, P.H. (1989). Extreme seasonality of births among nomadic Turkana pastoralists. Am J Phys Anthropol 79(1): 103-115. doi:10.1002/ajpa.1330790111.

Mulder, M.B. (1992). Demography of pastoralists: Preliminary data on the Datoga of tanzania. Human Ecology 20: 383-405.

Panter-Brick, C. (1996). Proximate determinants of birth seasonality and conception failure in Nepal. Population Studies 50(2): 203-220. doi:10.1080/0032472031000149306.

Pullum, T. (2006). An Assessment of Age and Date Reporting in the DHS Surveys, 19852003. Methodological Reports No. 5, Macro International Inc., Calverton, Maryland.

Règnier-Loilier, A. and Rohrbasser, J.M. (2011). Y a-t-il une saison pour faire des enfants? Population et Sociètès 474.

Schoumaker, B. (2011). Omissions of births in dhs birth histories in sub-Saharan Africa. Presented at 2001 Annual PAA conference in Washington D.C.

Torche, F. and Corvalan, A. (2010). Seasonality of birth weight in Chile: Environmental and socioeconomic factors. Annals of Epidemiology 20(11): 818-826. 


\section{Appendix A}

Figure 3: $\quad$ The periodicity of the de-trended monthly amplitude from 1980 to latest available date, using spectral analysis. The significance of the peaks was evaluated against a randomized spectrum. Significant peaks are those that rise above the confidence intervals (blue area).
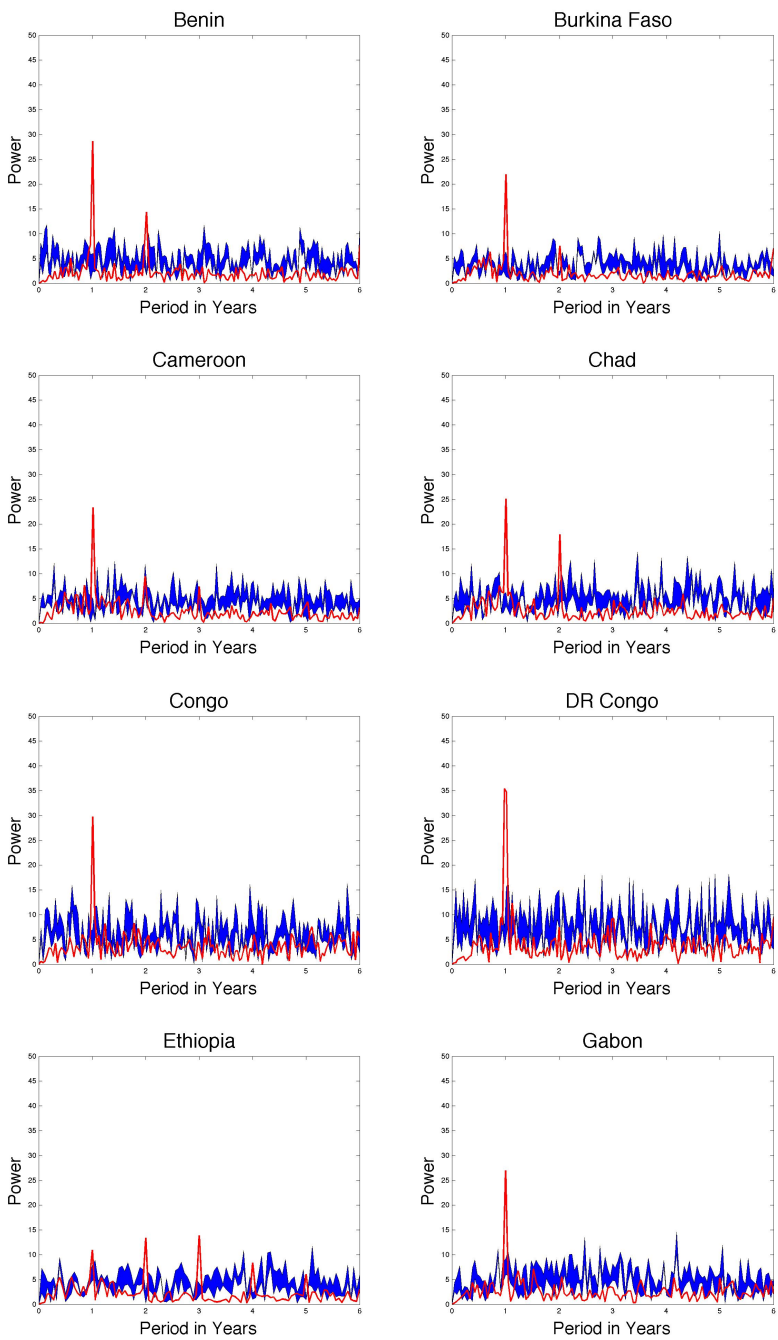

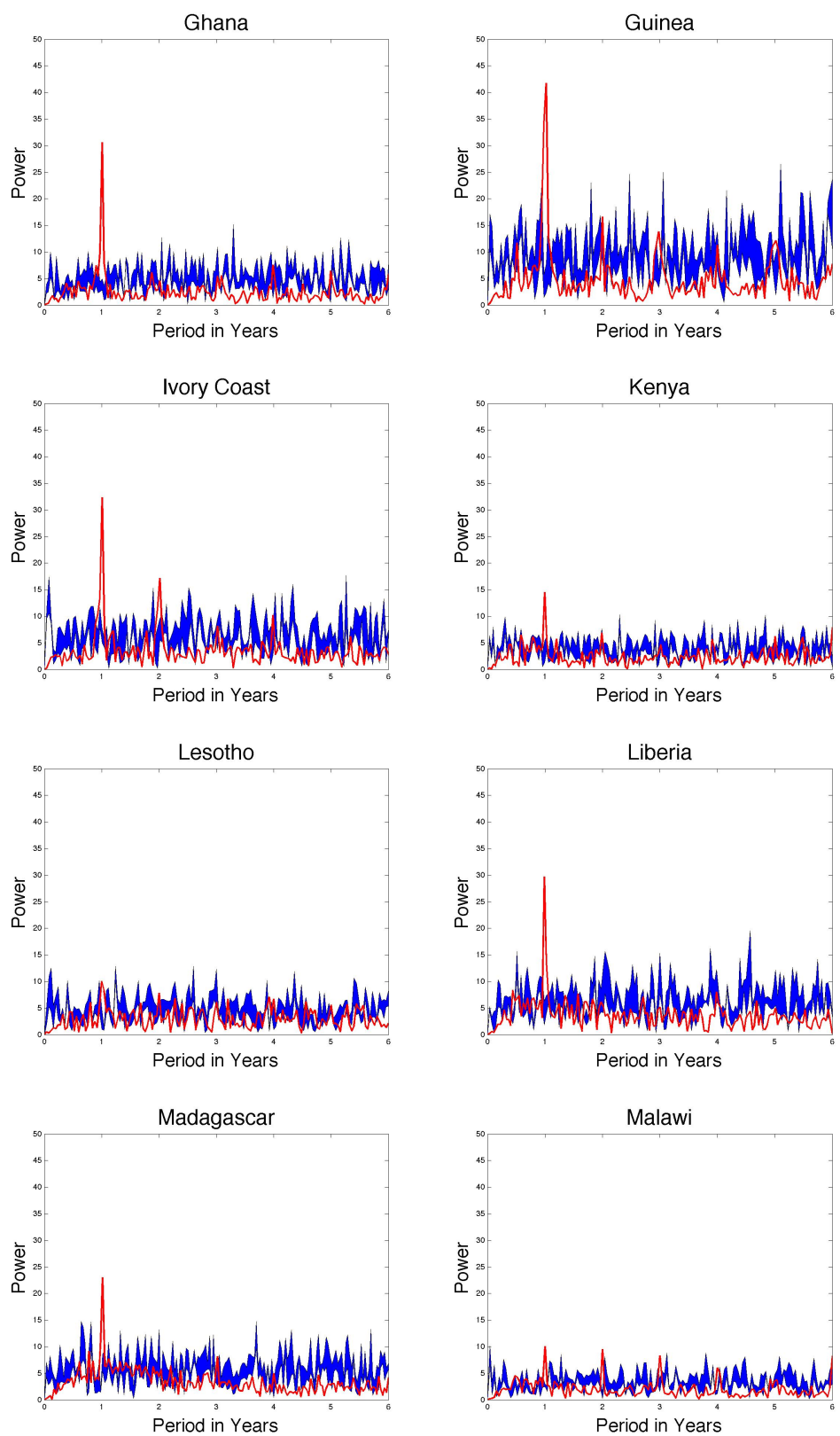
Dorélien: Birth seasonality in Sub-Saharan Africa
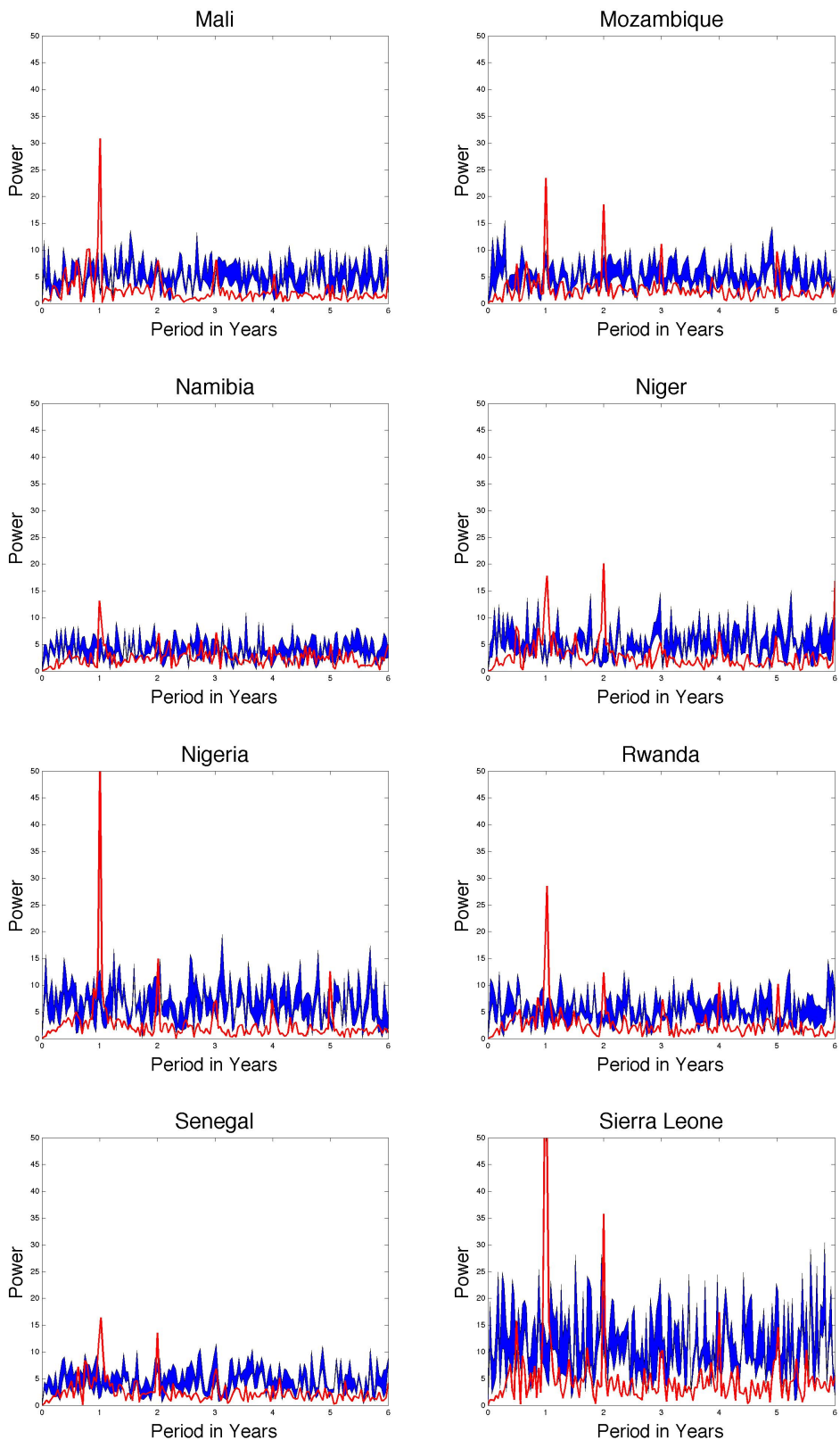

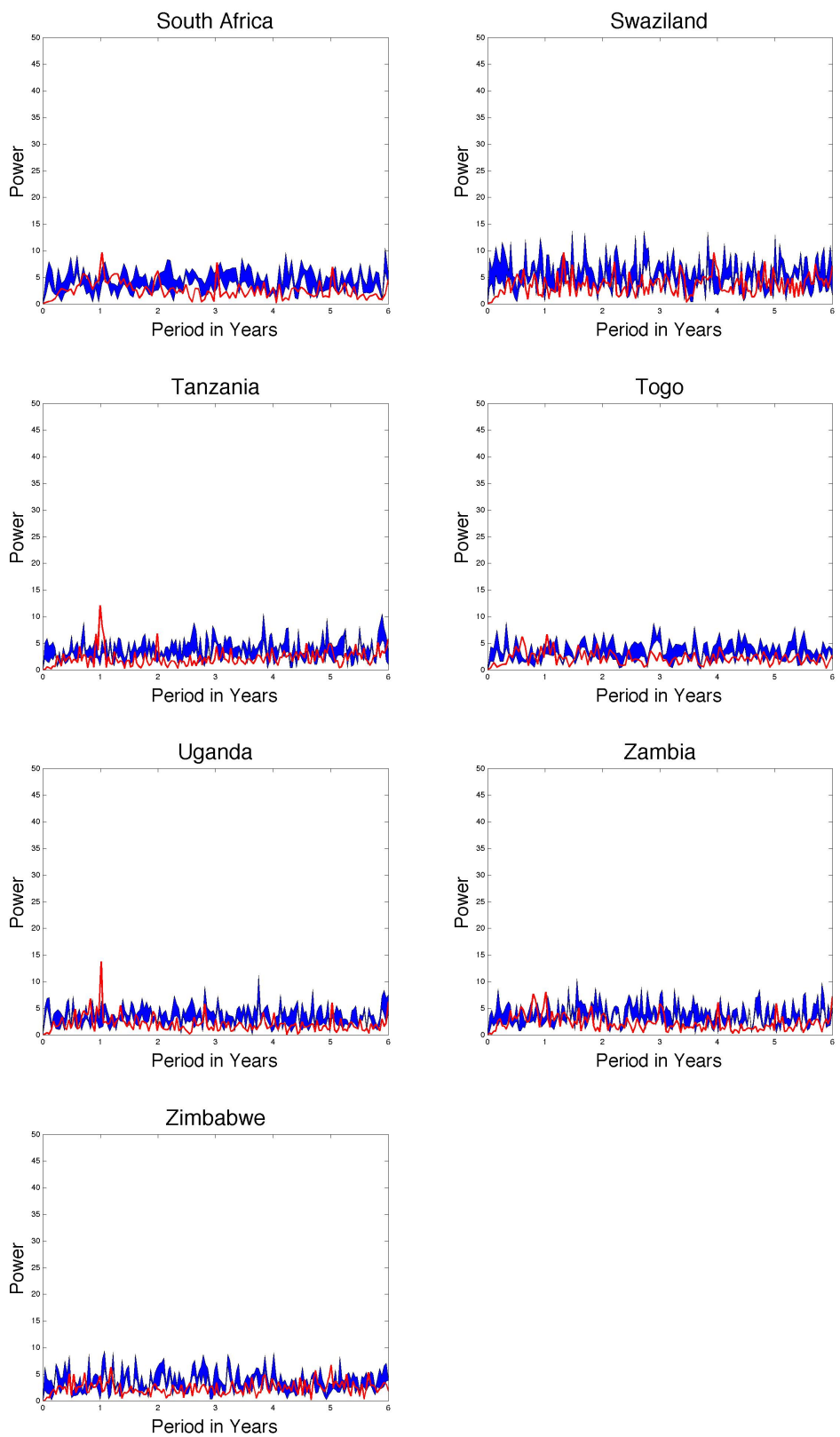
Dorélien: Birth seasonality in Sub-Saharan Africa

\section{Appendix B}

Figure 4: $\quad$ Birth seasonality pattern by country $($ black $=1980-1990$, red $=$ 1990-2000). The figures are grouped by region. Dates near country names indicate the earliest and latest surveys used in each country.
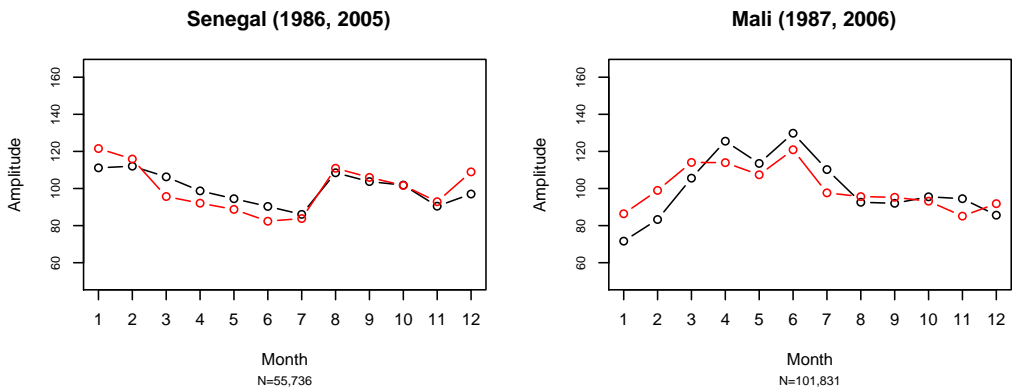

Niger $(1992,2006)$

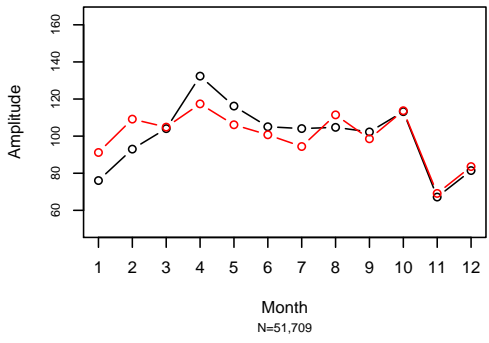

Chad (1996, 2004)

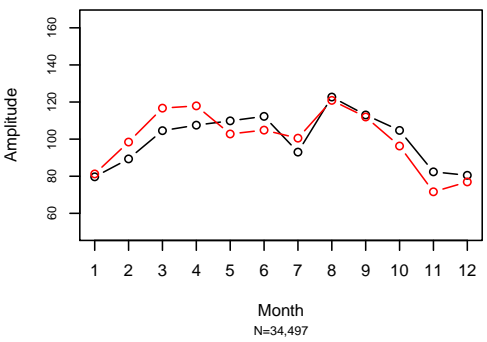

Burkina Faso (1993, 2003)

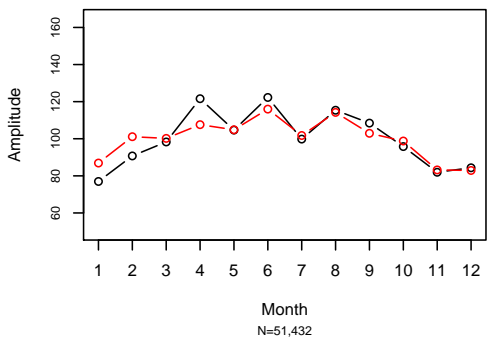

(a) Sahel 
Guinea (1999, 2005)

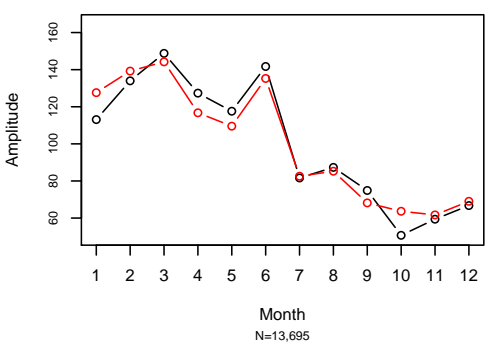

Liberia $(1986,2007)$

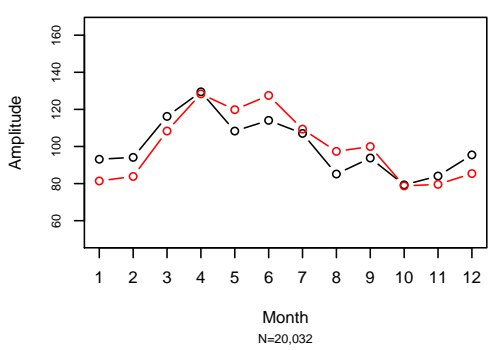

Ghana $(1988,2008)$

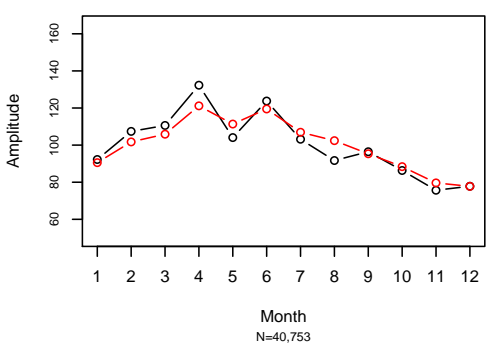

Benin (1996, 2006)

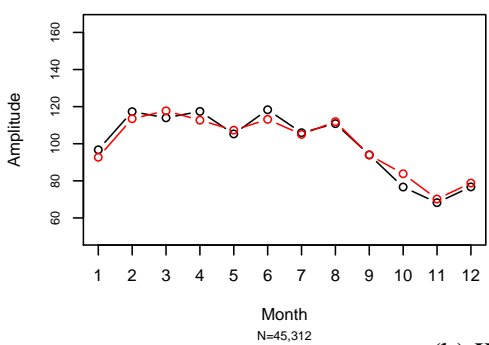

Sierra Leone (2008)

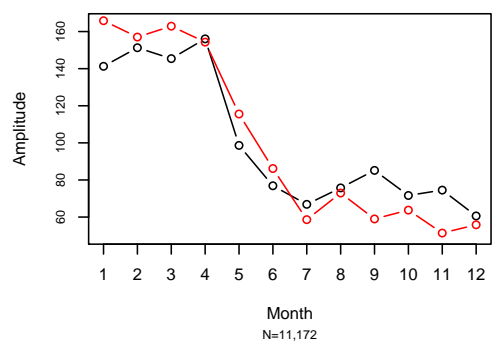

Ivory Coast $(1994,2005)$

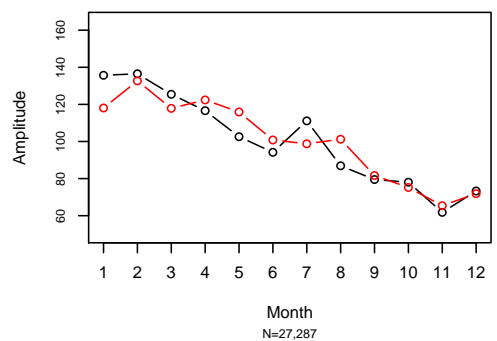

Togo $(1988,1998)$

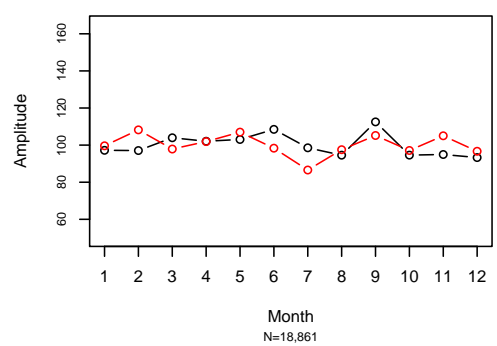

Nigeria $(1990,2008)$

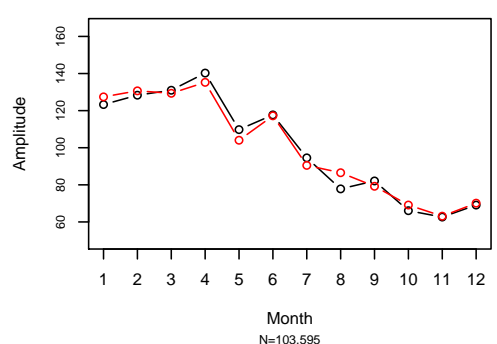

(b) West Africa 
Dorélien: Birth seasonality in Sub-Saharan Africa
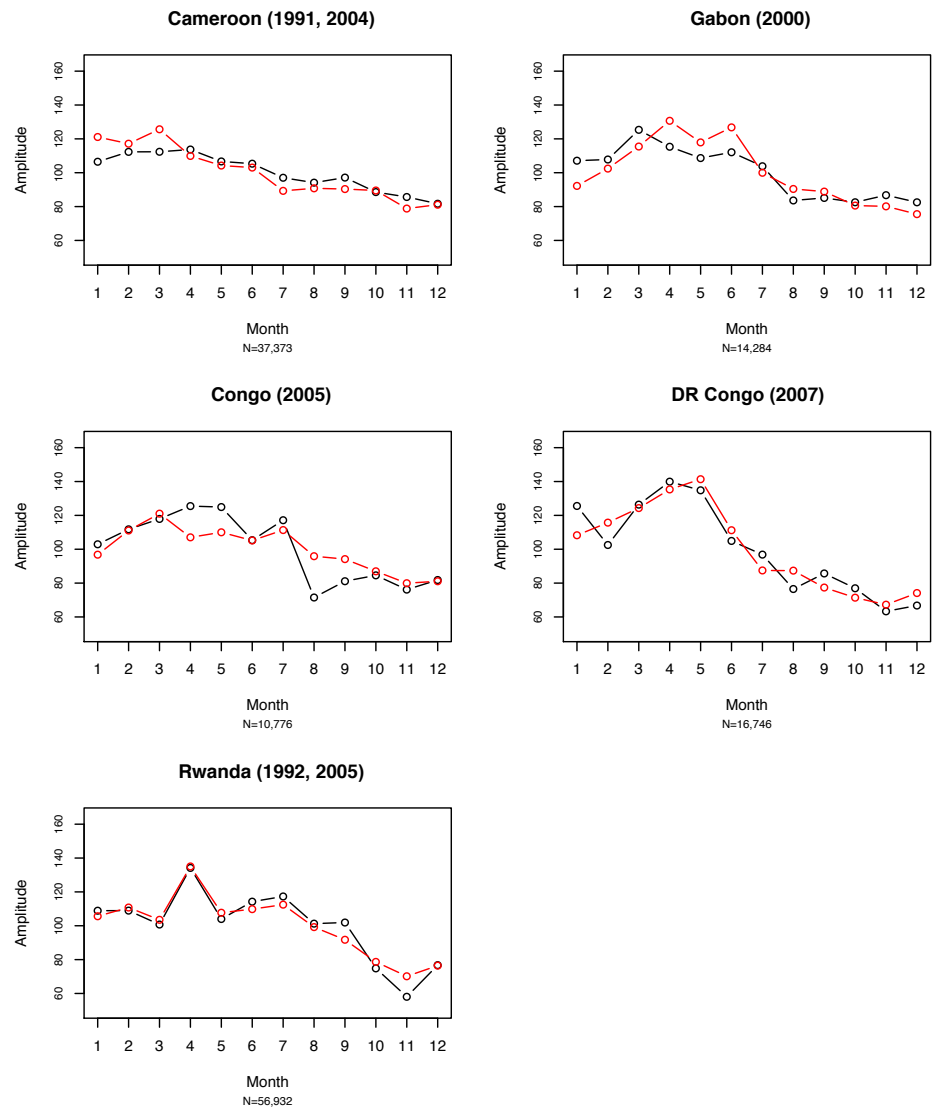

(c) Central Africa 
Ethiopia (2000, 2005)

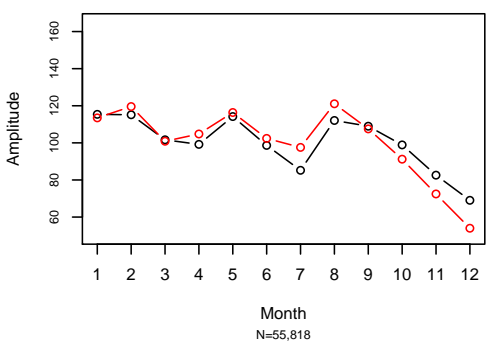

Uganda $(1988,2006)$

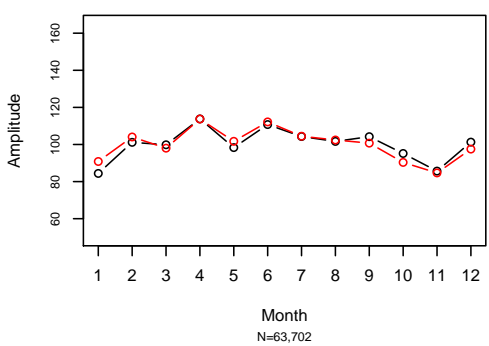

Madagascar (1992, 2009)

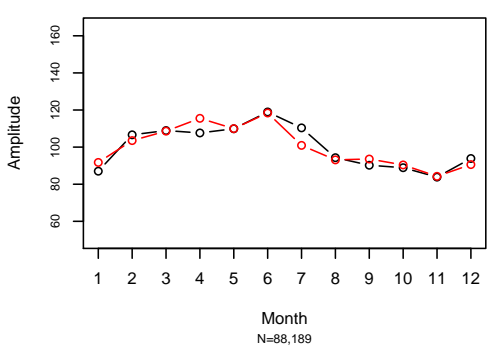

Kenya (1989, 2009)

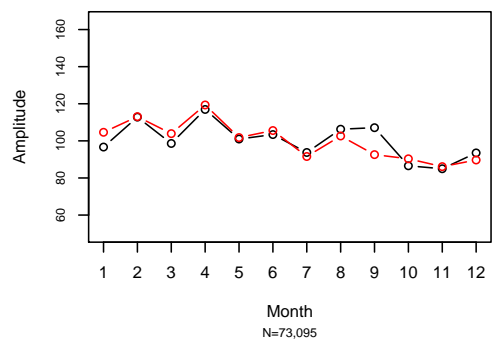

Tanzania $(1991,2008)$

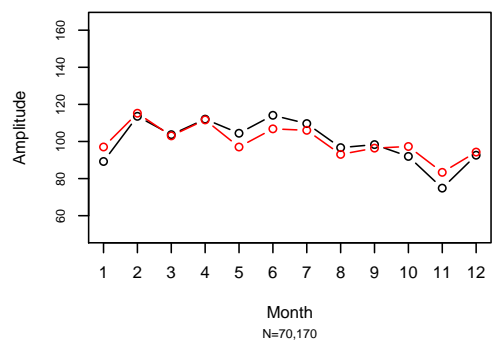

(d) East Africa 
Dorélien: Birth seasonality in Sub-Saharan Africa

Mozambique $(1997,2003)$

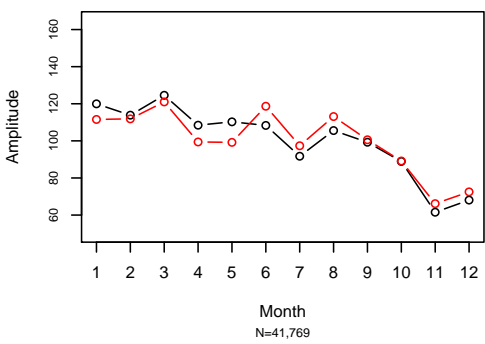

Zambia $(1992,2007)$

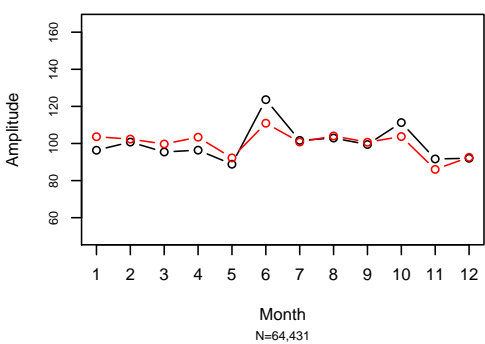

Namibia $(1992,2007)$

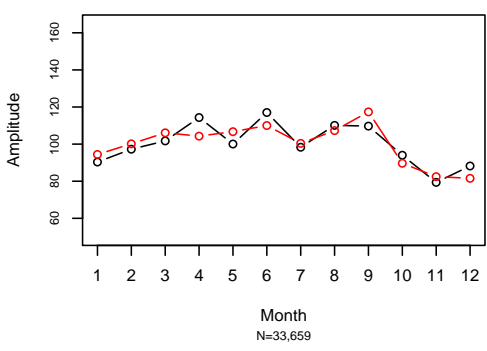

Swaziland (2006/7)

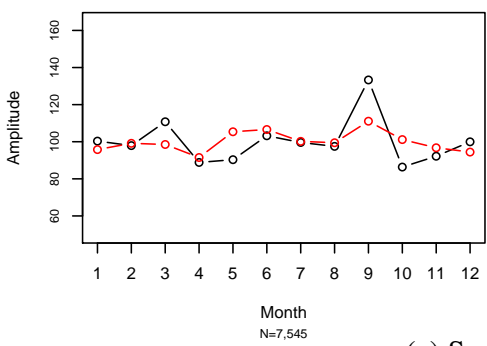

(e) Southern Africa
Malawi (1992, 2004)

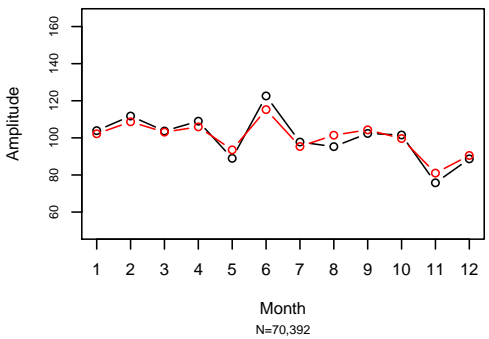

Zimbabwe (1988, 2006)

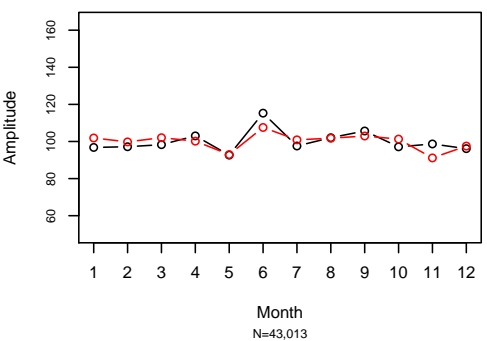

South Africa (1998)

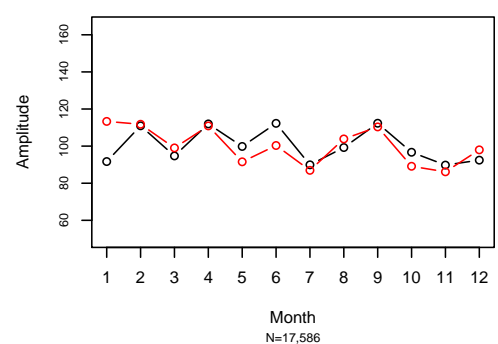

Lesotho (2004)

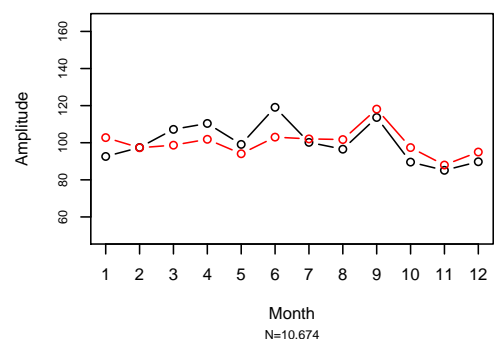

Month
$N=10,674$ 


\section{Appendix C}

Figure 5: $\quad$ Birth seasonality pattern by ecological zone $($ black $=1980-1990$, red $=1990-2000$ ). The figures are grouped by zone type.
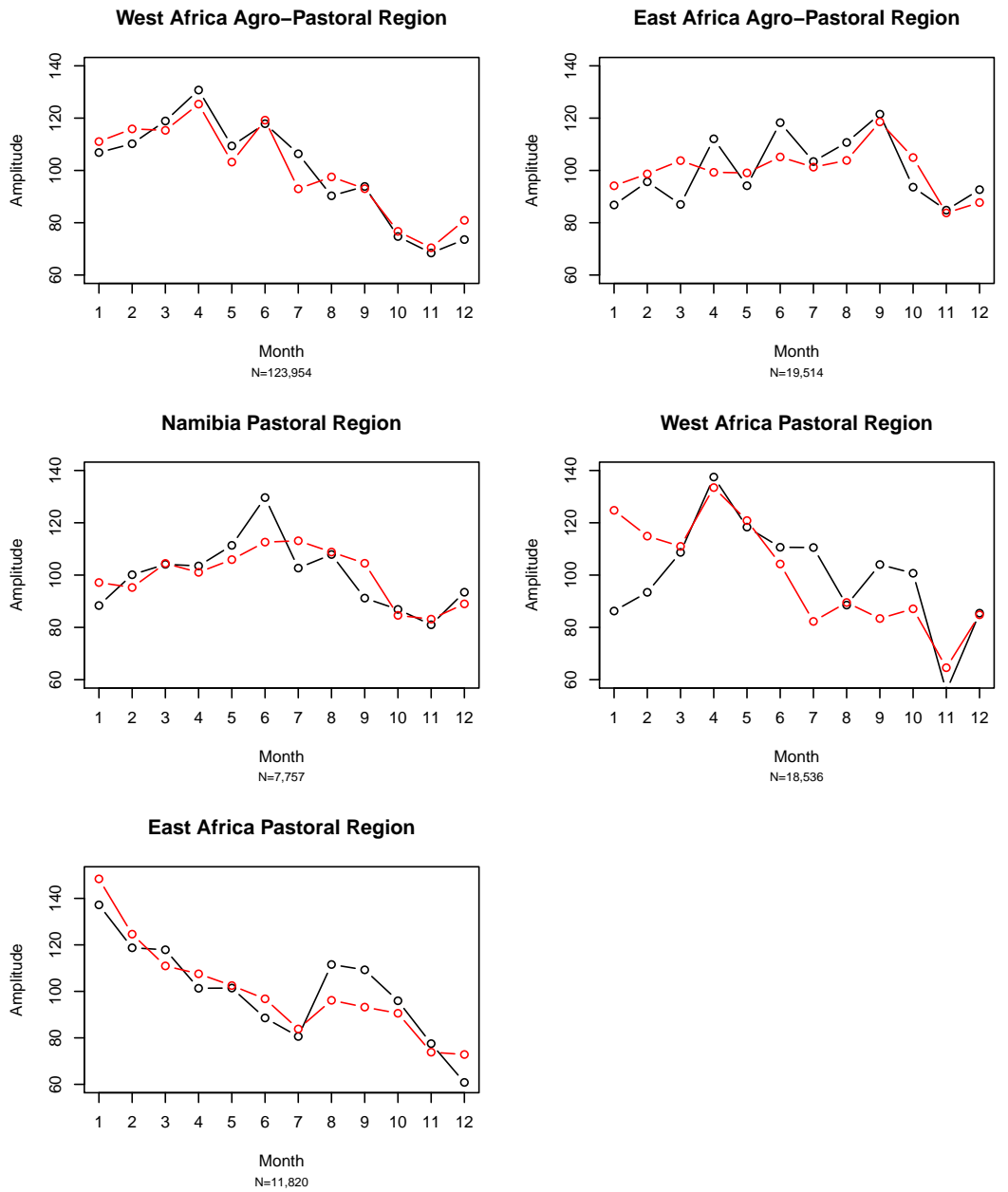

(a) Pastoral 
Dorélien: Birth seasonality in Sub-Saharan Africa
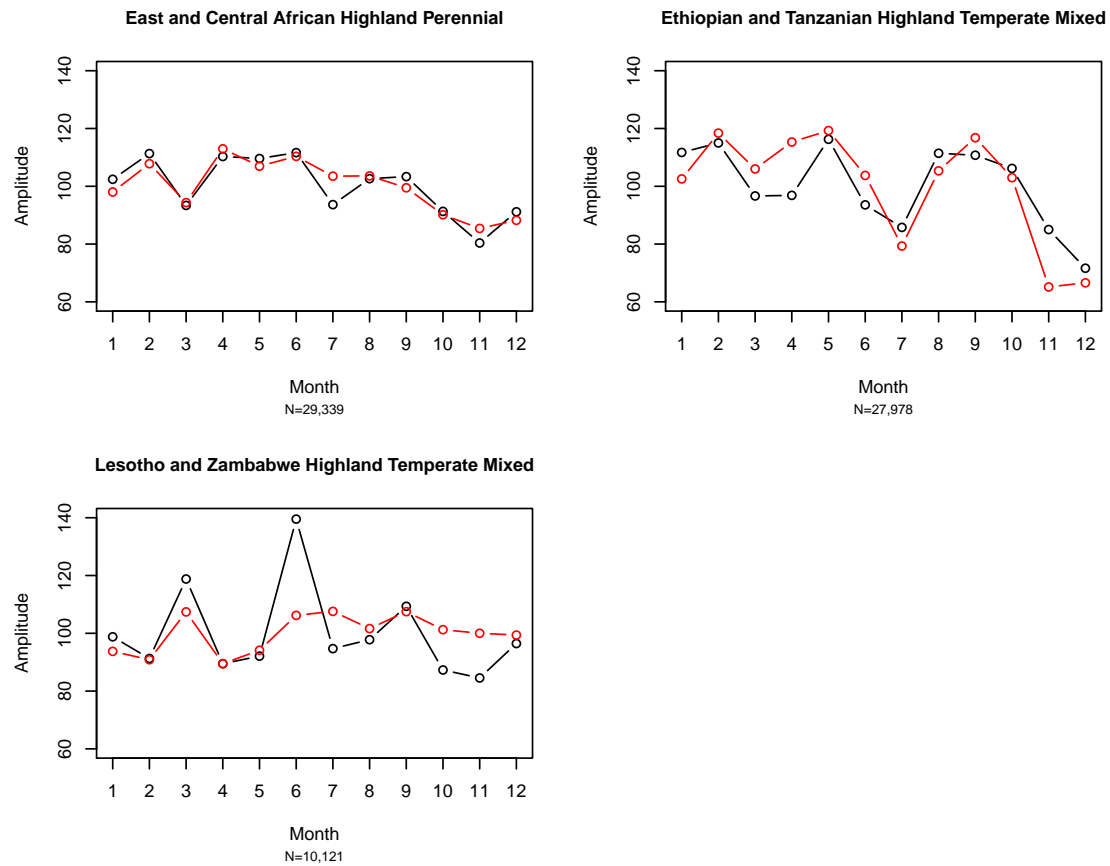

(b) Highlands 
Demographic Research: Volume 34, Article 27
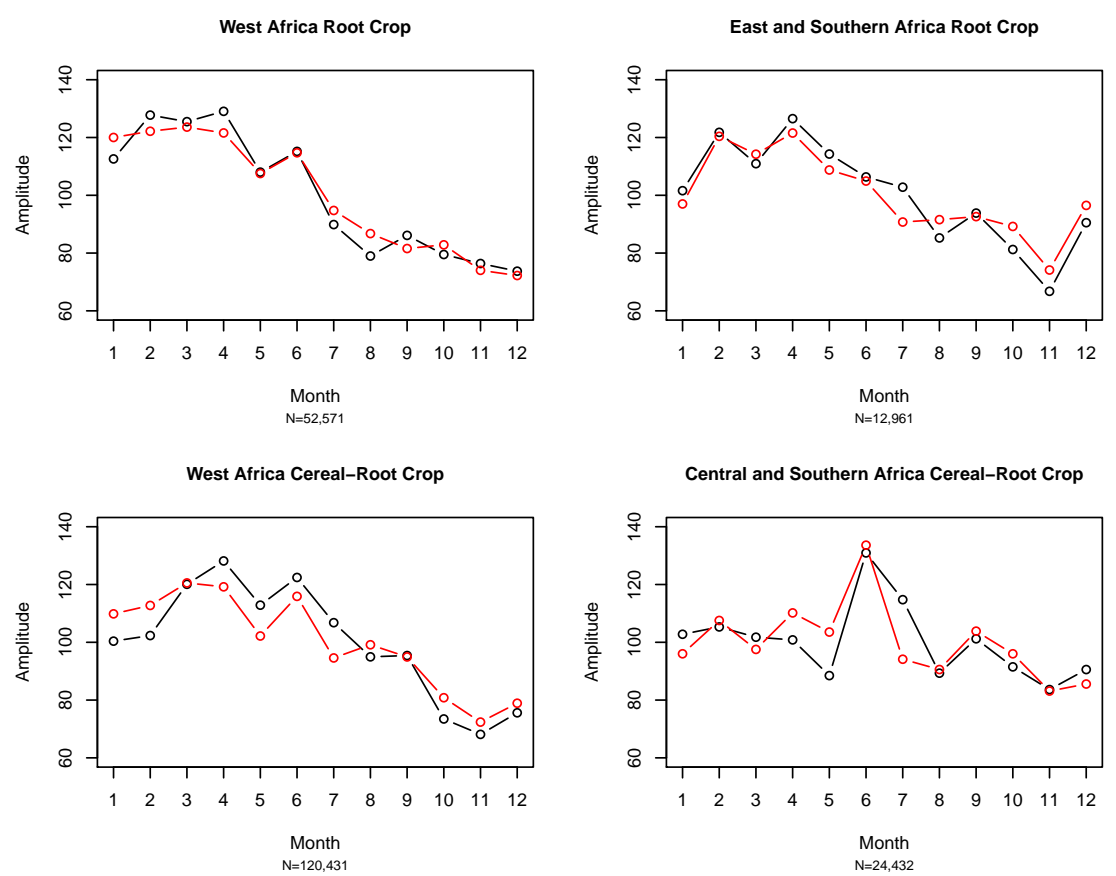

(c) Root Crops 
Dorélien: Birth seasonality in Sub-Saharan Africa
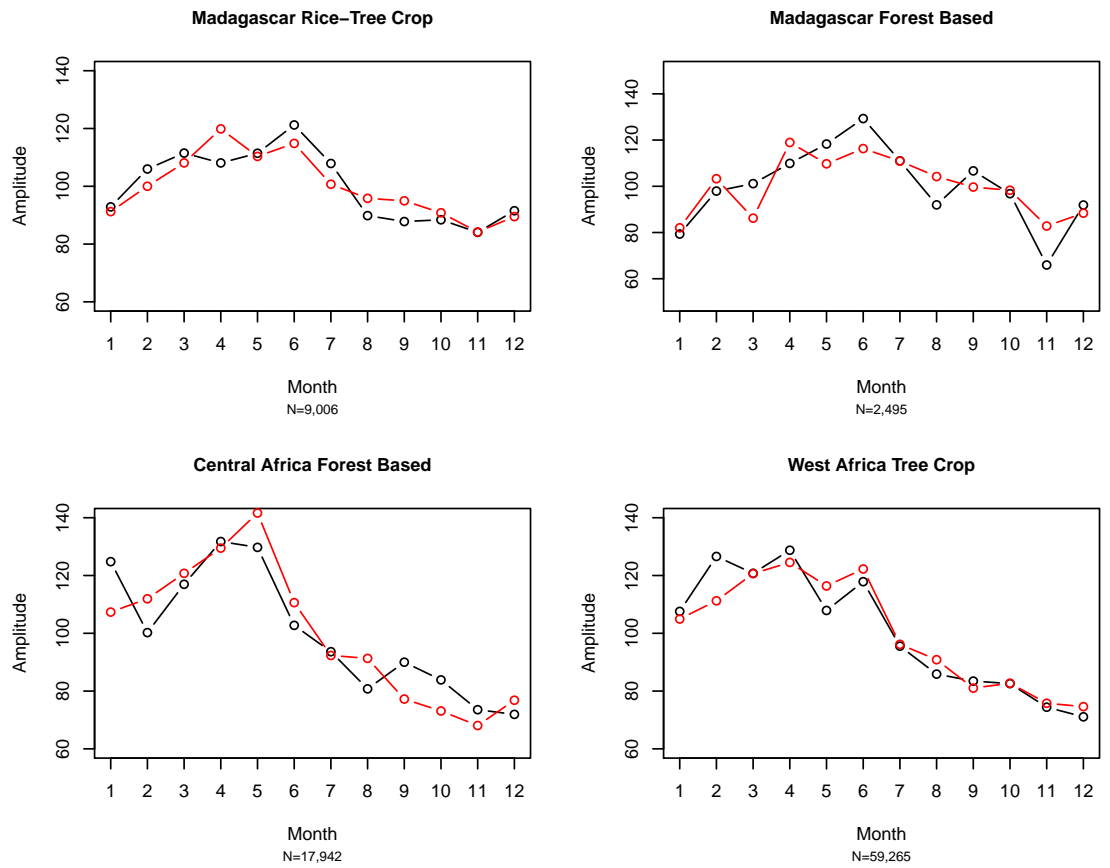

(d) Forest Based and Tree Crops 

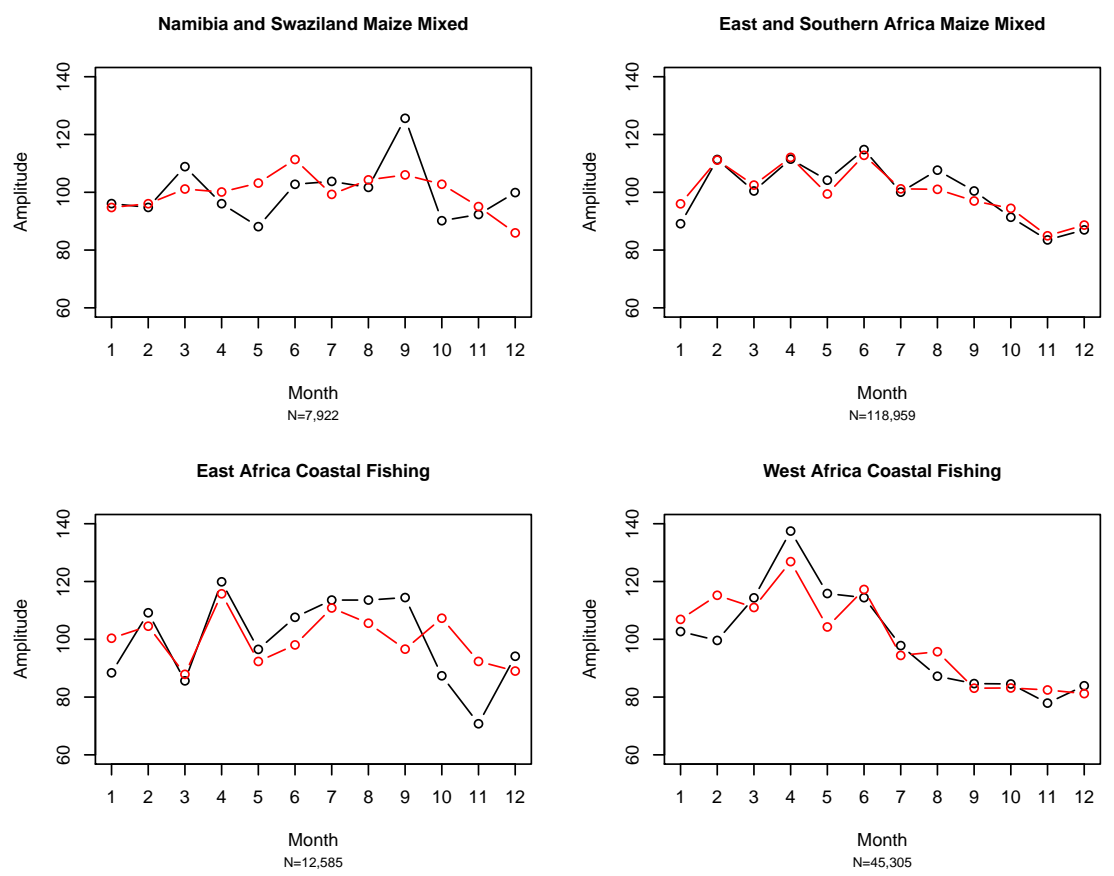

(e) Maize and Fishing 


\section{Appendix D}

Figure 6:

The periodicity of the de-trended monthly amplitude for ecological zones from 1980 to latest available date, using spectral analysis. The significance of the peaks was evaluated against a randomized spectrum. Significant peaks are those that rise above the confidence intervals (blue area).
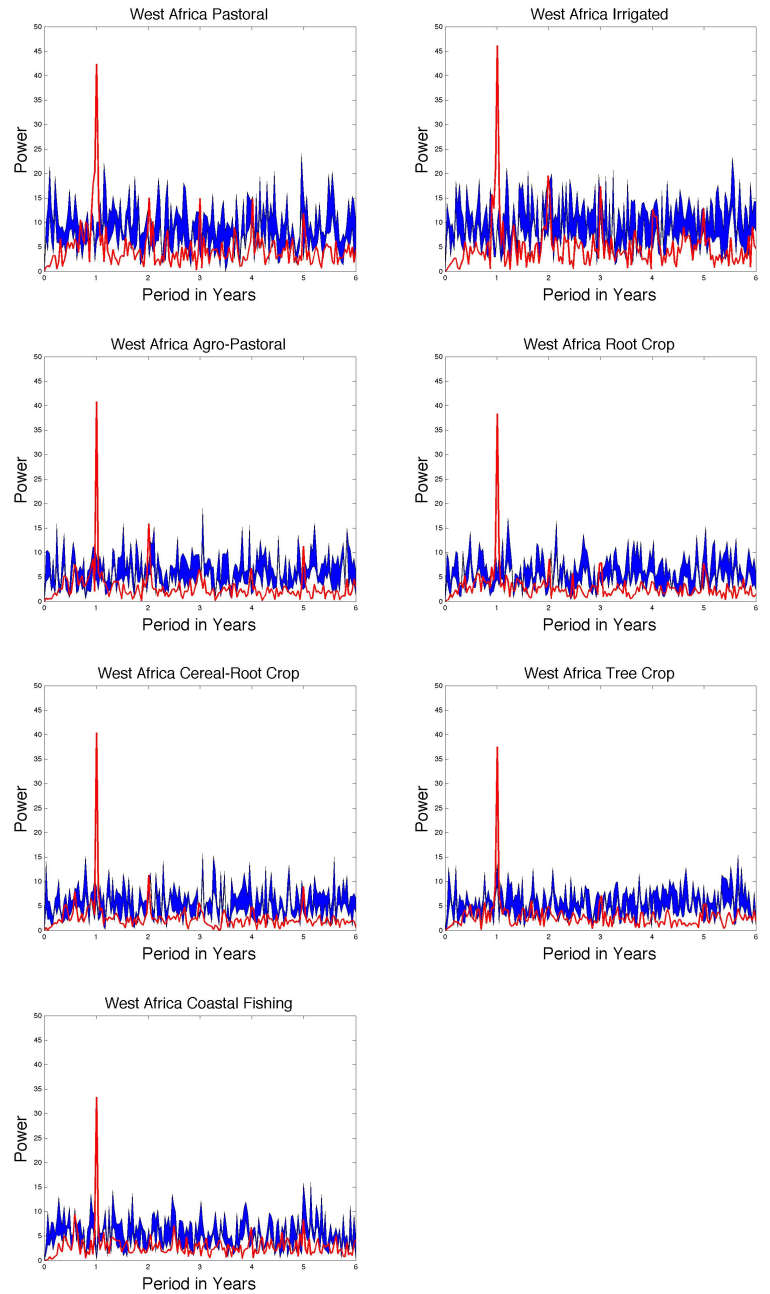
Demographic Research: Volume 34, Article 27
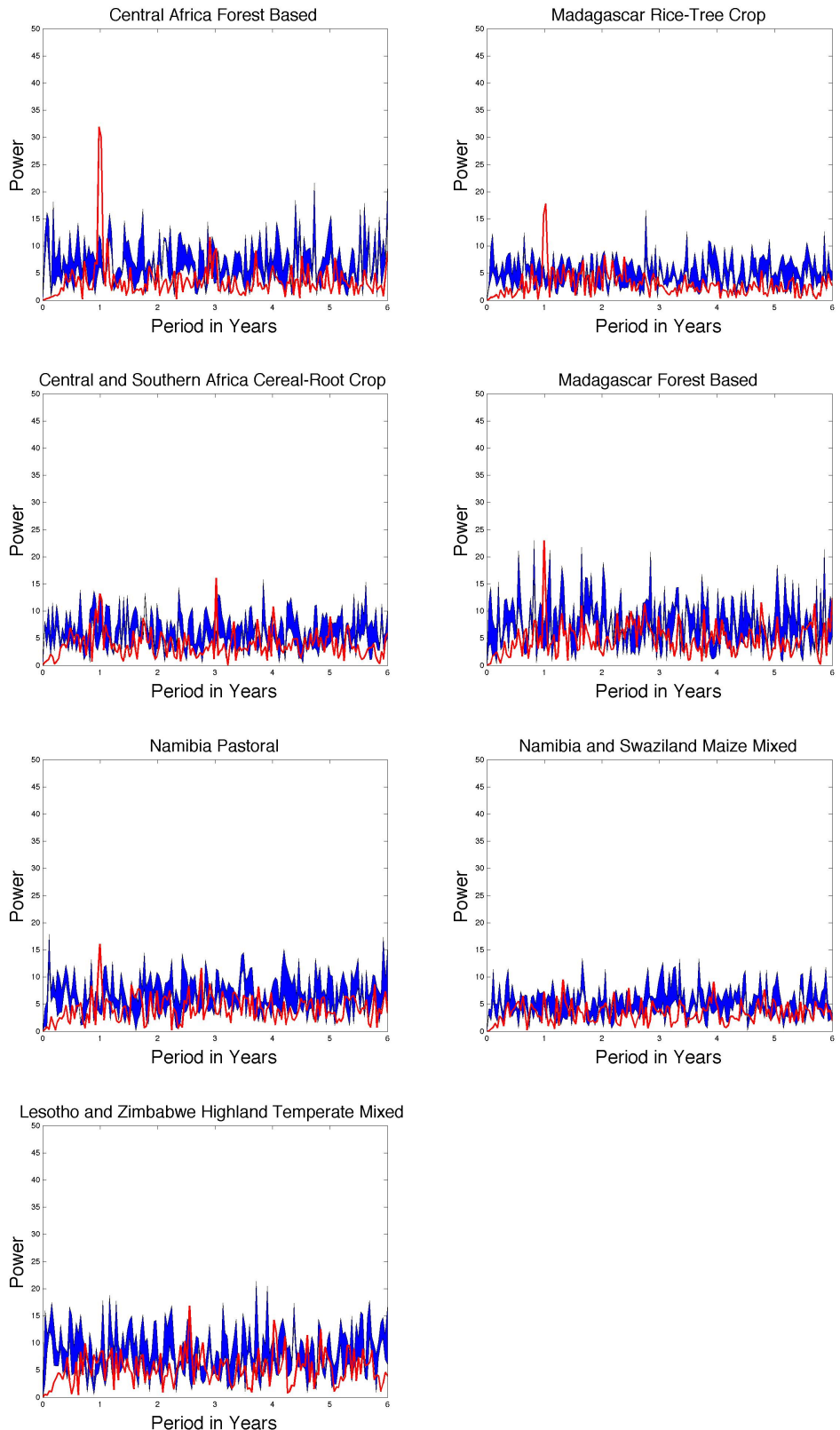
Dorélien: Birth seasonality in Sub-Saharan Africa
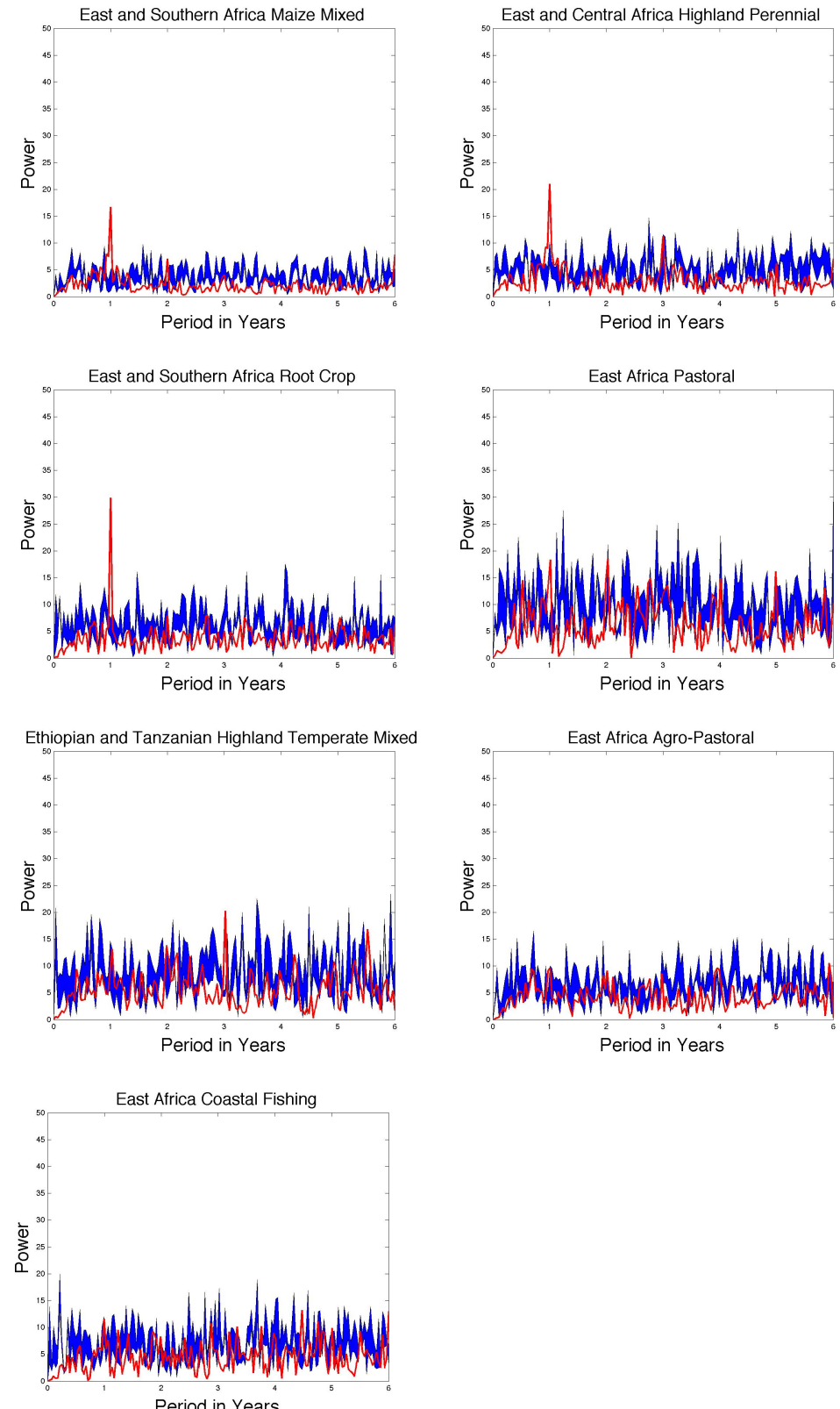